\title{
The thermodynamics of and strengthening due to co-clusters: general theory and application to the case of $\mathrm{Al}-\mathrm{Cu}-\mathrm{Mg}$ alloys
}

\author{
M.J. Starink and S.C. Wang \\ Materials Research Group, School of Engineering Sciences, \\ University of Southampton, Southampton S017 1BJ, UK
}

submitted 13 Aug 2008; accepted 19 Jan 2009

\begin{abstract}
Co-clusters in ternary or higher order metallic alloys are metastable structures involving two or more distinct alloying atoms that retain the structure of the host lattice. A thermodynamic model based on a single interaction energy of dissimilar nearest neighbour interaction energy is presented, and a model for the strengthening due to these co-cluster dimers is derived. The model includes a new treatment of (short-) order strengthening relevant to these co-clusters and further encompasses modulus hardening and chemical hardening. The models are tested against data on a wide range of $\mathrm{Al}-\mathrm{Cu}-\mathrm{Mg}$ alloys treated at temperatures between 20 and $220^{\circ} \mathrm{C}$. Both quantitative calorimetry data on the enthalpy change due to co-cluster formation and strengthening due to co-clusters is predicted well. It is shown that in general (short-range) order strengthening will be the main strengthening mechanism.
\end{abstract}

Keywords: Ageing; nanostructure; modelling; thermodynamics; short range ordering

\section{Introduction}

\section{Clusters, co-clusters and their strengthening in metallic alloys}

The prevailing theory of strengthening of metallic alloys as developed since the 1930s recognises the contributions to the critical resolved shear stress of grains with dilute compositions as being due to the obstacles to dislocation motion in the form of solute atoms and stable or metastable second phases. These second phases often form in a precipitation process from a supersaturated solution, and several metastable structures can appear before ultimately the stable phase or phases are formed. These precipitates can be very small: precipitates as small as 10 atoms have been proposed. These small precipitates are effectively formed from a metastable solution through a solute clustering process, i.e. the clustered solute atoms are situated on position of the host lattice. If the clusters formed involve two alloying elements, the term co-clusters is employed; the simplest form of a co-cluster is a dimer (Fig. 1). In most microstructural investigation techniques, including transmission electron microscopy (TEM) and high resolution electron microscopy (HREM) clusters of this small size can not be resolved. But atom probe experiments do allow detection of the clusters, and in the past two decades, 3D atom probe has allowed the identification of clusters as small as 10 atoms in alloys such as in maraging Fe-20Ni-1.8Mn-1.5Ti-0.59Al steel [1], Fe-C-Mn$\mathrm{Si}$ steels with additions of $\mathrm{Nb}, \mathrm{Al}$ and $\mathrm{Mo}$ [2], Al-Zn-Mg(-Cu) [3,4], Al-Mg-Ag [5], Al-Si-Mg [6] 
and Al-Cu-Mg based alloys [7] (in the aluminium alloys the term Guinier-Preston (GP) zone has been associated with these clusters). The picture starting to emerge from two decades of atom probe work is that whenever the early stages of decomposition of solution treated alloys with significant alloying additions (significant in terms of influencing mechanical properties) are investigated, clusters or co-clusters are in most cases detected.
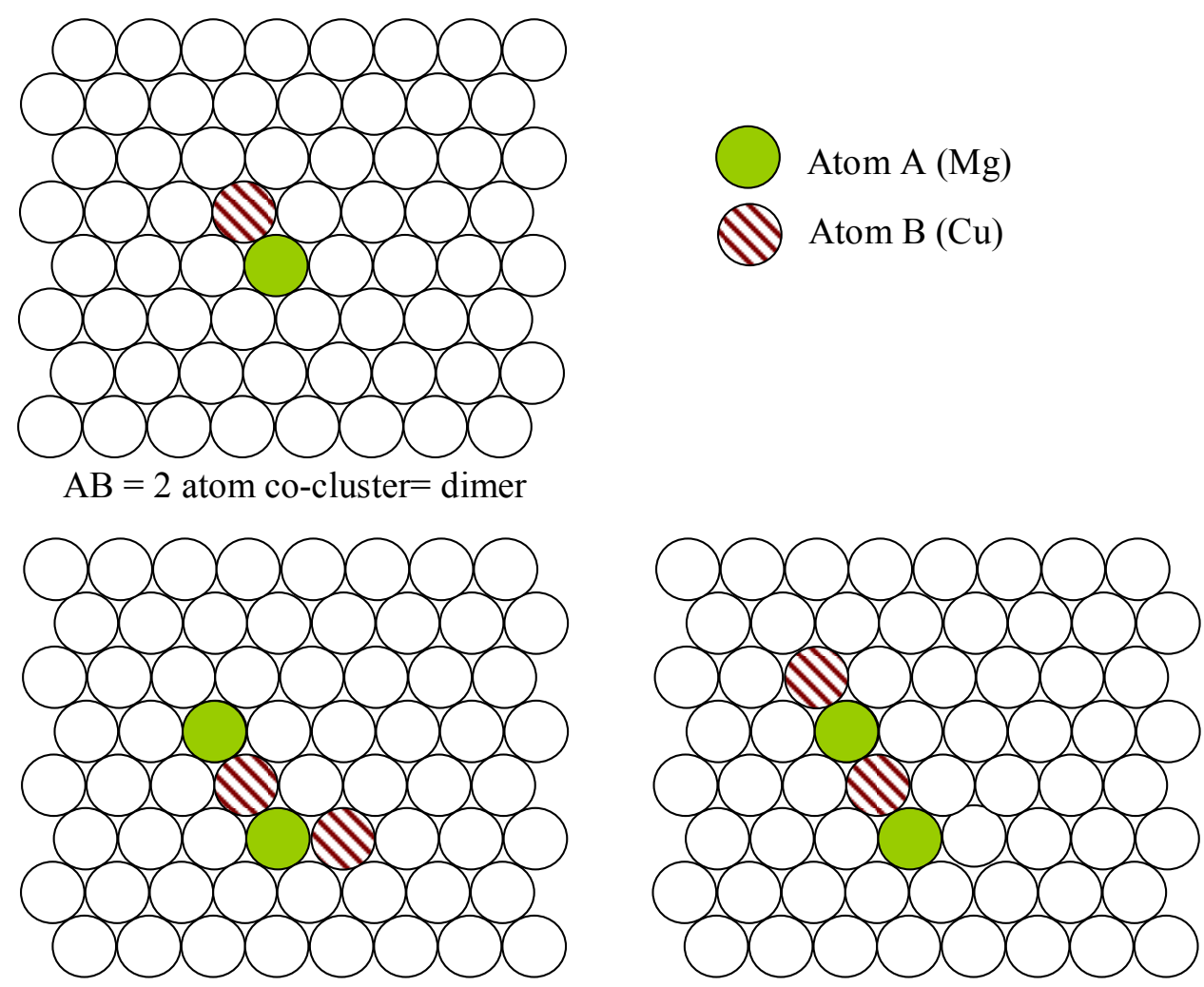

$\mathrm{AB}+\mathrm{AB}(\pi / 3) 4$ atom co-cluster

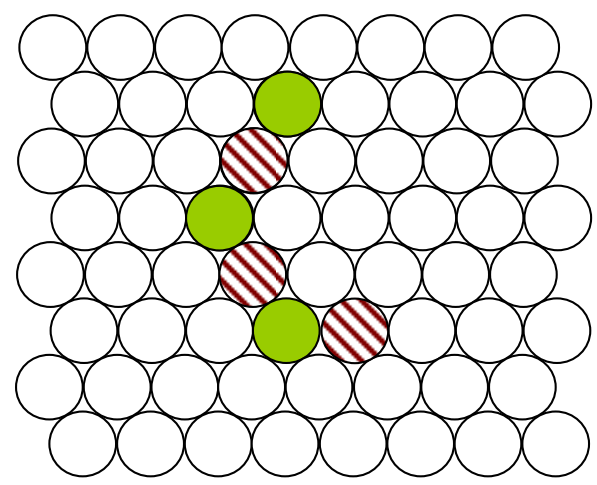

$\mathrm{AB}+\mathrm{AB}(0) 4$ atom co-cluster

$\mathrm{AB}+\mathrm{AB}(\pi / 3)+\mathrm{AB}(\pi / 3)$ co-cluster

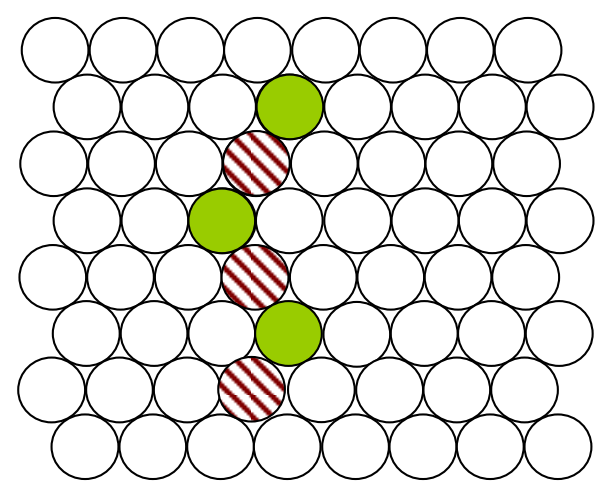

$\mathrm{AB}+\mathrm{AB}(\pi / 3)+\mathrm{AB}(-\pi / 3)$ co-cluster

Fig. 1 A 111 plane in an FCC lattice in a ternary alloy containing co-clusters, with a notation describing the co-cluster constellation.

Hardening due to the clusters and co-clusters has been invoked as a qualitative explanation for strengthening of a range of alloys. However, attempts at providing a quantitative explanation of the strengthening effect of clusters and co-clusters have been limited and have been based on a limited physical basis. In this paper we will present a theory for the thermodynamics of and the 
strengthening due to co-clusters in metallic alloys; thus providing the theoretical basis for this strengthening mode in metallic alloys. The model is applied to $\mathrm{Al}-\mathrm{Cu}-\mathrm{Mg}$ alloys and tested against an extensive amount of published and new data. This alloy system is chosen for the interlinked reasons of alloy availability, data availability, relative ease of sample preparation and analysis, and importance in engineering applications. Al-Cu-Mg alloys are extensively used for lightweight, fatigue resistant structures such as lower wing skins and fuselage of airplanes [8,9] as well as a range of other applications. The general validity of the theory is thought to not be limited to the investigated alloys: the developed theory will indicate that co-cluster formation should occur in many supersaturated alloys.

The method of choice for identifying thermodynamics of the co-clusters is calorimetry, as through calorimetry both the enthalpy changes of the system and the metastable solvi can be determined. However, calorimetry, in isolation, can not identify clusters or phases. Indications for the existence of co-clusters have mostly been obtained with 3 dimensional atom probe (3DAP) (and more recently supported by Nuclear Magnetic Resonance (NMR) [10,11], X-ray absorption spectroscopy (XAS) [12] and positron annihilation lifetime spectroscopy (PALS) studies [13]).

\section{Co-clusters in Al-Cu-Mg alloys}

For solution treated $\mathrm{Al}-\mathrm{Cu}-\mathrm{Mg}$ based alloys with composition in the $\alpha+\mathrm{S}$ phase field, room temperature hardening occurs within several days (several weeks if the $\mathrm{Cu}$ content is very low) and hardening during artificial ageing is very fast, typically within minutes $[14,15,16]$. Whilst diverging explanations have been proposed for this phenomenon, recent experiments in combination with careful reassessment of existing evidence has indicated that the phenomenon is caused by $\mathrm{Cu}-\mathrm{Mg}$ co-clusters [7]. In assessing the experimental evidence, we should note that immediately after the rapid hardening and during the room temperature hardening in these $\mathrm{Al}-\mathrm{Cu}-\mathrm{Mg}$ based alloys no distinct precipitate phase can be detected by conventional TEM [17], but differential scanning calorimetry (DSC) experiments clearly show a change in the free energy of the alloys indicating that a significant fraction of the dissolved atoms have been involved in a reaction $[18,19]$. There are no reports of any ordered structures at this stage. Results from several atom probe field ion microscopy (APFIM) and three-dimensional atom probe (3DAP) studies reveal $\mathrm{Cu}-\mathrm{Mg}$ co-clusters of typically $1 \mathrm{~nm}$ diameter (10-40 atoms) [7,20,21] which by some authors are held directly responsible for the rapid hardening reaction [20,21]. Information on the composition of $\mathrm{Cu}-\mathrm{Mg}$ coclusters is limited. Ringer et al. [20,21] observed that in a high purity Al-1.7at.\%Mg-1.1at.\% $\% \mathrm{Cu}$ aged for $5 \mathrm{~min}$ at $150^{\circ} \mathrm{C}$ clusters with high $\mathrm{Cu}: \mathrm{Mg}$ ratios existed, whilst Starink et al. [7] found that in an $\mathrm{Al}-2.78 \mathrm{wt} \% \mathrm{Cu}-0.44 \mathrm{wt} \% \mathrm{Mg}$ and in an $\mathrm{Al}-2.78 \mathrm{wt} \% \mathrm{Cu}-1.05 \mathrm{wt} \% \mathrm{Mg}$ (both alloys are commercial purity with $\mathrm{Mn}$ additions) the $\mathrm{Mg} / \mathrm{Cu}$ ratio of the clusters varied from one cluster to another. They also contain vacancies [17].

Due to the discovery of rapid hardening Al-Cu-Mg based alloys early in the $20^{\text {th }}$ century, and its subsequent extensive application, the reaction has been extensively studied and it can be considered one of the classic issues in metallurgy. But early researchers did not have the benefit of HREM and atom probe analysis, and some unsubstantiated assumptions have entered the literature. Especially 
in pre-1990s work early hardening reaction in Al-Cu-Mg alloys was attributed to the formation of $\mathrm{Cu}$ and $\mathrm{Mg}$ containing structures which were termed Guinier-Preston-Bagaryatski (GPB) zones [22]. This term was coined in the 1950s and has been used for decades without evidence of what they may consist of. Consequently a range of often conflicting interpretations of these GPB zones have appeared in the literature. Only very recently a clearer picture of GPB zones using scanning transmission electron microscopy (STEM) supported by first principle modelling of the structures is starting to emerge [23]. It is the opinion of the authors that due to differing interpretation of its meaning and the lack of experimental evidence, the term 'GPB zone', as related to the rapid hardening in $\mathrm{Al}-\mathrm{Cu}-\mathrm{Mg}$ based alloys, has become an obstacle to the proper understanding of the mechanisms for rapid hardening. Hence we will here avoid using the term as much as possible.

\section{A model for the thermodynamics of and strengthening due to co-clusters}

\section{The thermodynamics of co-clusters}

For modelling the thermodynamics of the co-clusters one may consider the possibility of the coclusters forming a range of possible constellations in the FCC lattice. From a virtually unlimited number of possible constellations, some possible constellations that are thought to be energetically favoured in Al-Cu-Mg alloys (see Discussion section) are illustrated in Fig. 1. The smallest cocluster is a dimer of nearest neighbours of dissimilar alloying atoms Fig. 1a. In considering an approach to modelling the thermodynamics, we considered three approaches to modelling in order of increasing complexity:

I. a regular solution model

II. a quasi-chemical model which takes nearest neighbour interactions into account (see e.g. [24]).

III. a first principles total energy calculation (FP-CVM) (see for instance [25]).

As described below, a dimer treated in a regular solution model (with a single bond energy), was found to fully explain all of a very extensive set of calorimetry data on $\mathrm{Al}-\mathrm{Cu}-\mathrm{Mg}$ alloys. Hence we will fully describe this treatment, and limit our consideration of more complex treatments to a brief discussion at the end of this subsection.

Within the regular solution model, the solvi of the phases and co-clusters in the ternary system can be derived as follows. Consider alloying elements $\mathrm{A}$ and $\mathrm{B}$ in a host metal $\mathrm{M}$, the total number of the respective elements in the system are $N_{\mathrm{A}}, N_{\mathrm{B}}$ and $N_{\mathrm{M}}$. The Gibbs free energy, $G$, of the system can be approximated as:

$$
G=H_{o}-N_{c l} \Delta H_{A-B}-T S
$$

where $N_{\mathrm{cl}}$ is the number of A-B dimers, $H_{\mathrm{o}}$ is a constant reference enthalpy and $\Delta H_{\mathrm{A}-\mathrm{B}}$ is the enthalpy of formation of an A-B dimer from the random solution, i.e. the enthalpy of the reaction in which one A atom and one B atom, originally in random solution, form an A-B dimer. The entropy of the system is proportional to the logarithm of the number of states $w$ in the system: 


$$
S=k_{B} \ln w=k_{B} \ln \left(\frac{N !}{\left(N_{M} !\left(N_{A}-N_{c l}\right) !\left(N_{B}-N_{c l}\right) !\right) 12 N_{c l} !}\right)
$$

where $k_{\mathrm{B}}$ is Boltzmann's constant. For equilibrium it holds $\partial G / \partial N_{\mathrm{cl}}=0$. Performing this derivation using the latter two equations (using the Stirling approximation $\ln N !=N \ln N-N$ ) then provides that at equilibrium:

$$
c_{A} c_{B}=\exp (-2) \exp \left[\frac{-\Delta H_{A-B}}{R T}\right]
$$

where $c_{\mathrm{A}}$ is the solubility (i.e. the equilibrium molar fraction) of element $\mathrm{A}$ in the $\mathrm{M}$ rich host lattice, $c_{\mathrm{B}}$ is the solubility of element $\mathrm{B}$ in the $\mathrm{M}$ rich host lattice. It can be noted that this corresponds to the more generally applied 'solubility product' equation:

$$
c_{A} c_{B}=C^{2} \exp \left[\frac{-\Delta H_{A-B}}{R T}\right]
$$

where $C$ is a constant. In the latter form, no attempt is made to fully analyse the entropy term, and only the entropy of the atoms belonging to the Al-rich phase is considered. Thus constant $C$, which is related, amongst others, to the entropy of the clusters or precipitates, is considered a fittable parameter. In a more general form, the solubility limits of co-clusters according to the regular solution of any complex $M_{m} A_{a} B_{b}$ is given as:

$$
c_{A}{ }^{a} c_{B}{ }^{b}=C^{2} \exp \left[\frac{-\Delta H_{M m A a B b}}{R T}\right]
$$

where $\Delta H_{\mathrm{MmAaBb}}$ is the enthalpy of formation of the $\mathrm{M}_{\mathrm{m}} \mathrm{A}_{\mathrm{a}} \mathrm{B}_{\mathrm{b}}$ complex, i.e. the enthalpy of the reaction in which $a$ atoms of type $\mathrm{A}, b$ atoms of type $\mathrm{B}$ and $\mathrm{m}$ atoms of type $\mathrm{M}$, originally part of the $\mathrm{M}$ rich phase, form an $\mathrm{M}_{\mathrm{m}} \mathrm{A}_{\mathrm{a}} \mathrm{B}_{\mathrm{b}}$ complex, which can be an ordered or disordered cluster or precipitate.

The latter two expressions can be tested through measurement of the heat evolved in the reactions of formation or dissolution of the clusters or precipitates. Particularly, when a calorimetry experiment is conducted such that the total heat evolved on completing of the co-clustering reaction is measured, exothermic heat evolved, $\Delta Q$, should then be given by:

$$
\Delta Q=\frac{\left(x_{A}^{o}-x_{A}\right)}{a} \Delta H_{M m A a B b}
$$

where $x_{A}^{o}$ is the composition of the M-rich phase at the start of the reaction, and $x_{\mathrm{A}}$ is the composition of the M-rich phase on completion of the reaction. $x_{\mathrm{A}}$ can be solved by considering that the composition during the reaction up to completion of the reaction is given by:

$$
x_{A}^{o}-x_{A}=\frac{a}{b}\left(x_{B}^{o}-x_{B}\right)
$$


whilst at completion:

$$
c_{A}{ }^{a} c_{B}{ }^{b}=x_{A}{ }^{a} x_{B}{ }^{b} \quad \text { (at completion of reaction) }
$$

Thus $x_{\mathrm{A}}$ can be solved from Eqs. 5, 7 and 8. (For particular values of the ratio $a: b$, the equations can be solved analytically, particularly $a=b=1$ simplifies the equations considerably, but in general a simple iterative scheme is needed.)

An alternative treatment suggested in the literature [24] involves a quasi-chemical model which takes nearest neighbour interactions into account. Analysis of this model (see Discussion section) showed that it can not explain all the experimental observations.

Solution treated commercial alloys typically contain some small amounts of undissolved intermetallic phases or dispersoids, which reduce the amount of solute atoms available for cocluster formation and subsequent precipitation. The composition of the supersaturated f.c.c. phase after solution treatment can generally be predicted from thermodynamic models (e.g. phase diagrams of the alloy). In commercial and commercial purity $\mathrm{Al}-\mathrm{Cu}-\mathrm{Mg}$ based alloys, $\omega-\mathrm{Al}_{7} \mathrm{Cu}_{2} \mathrm{Fe}$, $\mathrm{S}-\mathrm{Al}_{2} \mathrm{CuMg}$ and $\mathrm{T}-\mathrm{Al}_{20} \mathrm{Cu}_{2} \mathrm{Mn}_{3}$ can be present [26,27]. A method for calculating the amounts of these phases is described in the Appendix. This method is applied for all model predictions.

\section{Strengthening due to co-clusters}

Clusters and co-clusters are shearable and hence the Orowan strengthening mechanism is not applicable. Several strengthening mechanisms related to obstacle shearing need to be considered:

a) Order strengthening (including stacking fault strengthening) or configurational strengthening

b) Modulus hardening

c) Chemical hardening

\section{Order strengthening}

The strengthening due to an ordered phase which contains short or long range order depends on the way the dislocations interact with the precipitate or clusters. If long range order is present, dislocations can travel in groups due to the anti phase boundary (APB) [28,29,30,31,32]. For the present case of co-cluster strengthening, the order can be considered to be extremely short ranged and as restoration of order by dislocations travelling in groups is not possible, dislocations will travel alone. The work done in deforming the lattice through movement of dislocations hampered by (co-)clusters equals the change in energy related to the short range order per unit area on slip planes, i.e. $[33,34]$ :

$$
\Delta \tau_{s r o}=\frac{\gamma_{s r o}}{b}
$$

where $\gamma_{\text {sro }}$ is the change in energy per unit area on slip planes (which in most cases are $\{111\}$ planes) on the passing of one dislocation (a.k.a. the diffuse interphase boundary energy [33,35]). In the analysis of $\gamma_{\text {sro }}$ we could attempt to include several orders of near neighbour interaction for 
instance through considering a cluster variation approach [36]. However, we will here use a simplified approach that considers only nearest neighbour interactions. This is done for the following reasons: i) we do not have sufficient accurate data to determine all the $\mathrm{k}^{\text {th }}$ interaction parameters, and ii) the simpler nearest neighbour method provides a more intuitively acceptable analysis, which is a benefit as several competing analysis of strengthening due to co-clusters have been accepted. We will consider here co-clusters that consist of a single pair of atoms $\mathrm{A}$ and $\mathrm{B}$. The amount of $\mathrm{A}$ atoms in the co-clusters is $y_{\mathrm{A}}$, the amount of $\mathrm{B}$ atoms in the co-clusters is $y_{\mathrm{B}}$. The amount of $\mathrm{A}$ atoms in the M-rich phase is $x_{\mathrm{A}}$, the amount of $\mathrm{B}$ atoms in the M-rich phase is $x_{\mathrm{B}}$. In the (M-rich) f.c.c. lattice structure each atom has 12 nearest neighbours and each atom adjacent to a slip plane will have 3 nearest neighbours on the other side of the $\{111\}$ slip plane. The area density of A-B nearest neighbour bonds crossing the slip plane is:

$$
\rho_{A-B}\left(n_{d}=0\right)=\frac{\left(y_{A}+y_{B}\right)}{S_{111}}=\frac{4\left(y_{A}+y_{B}\right)}{\sqrt{3} b^{2}}
$$

where $S_{111}$ is the area on the 111 plane occupied by one atom. On passing of one dislocation through the AB co-cluster a part of the A-B bonds present before the passing will be destroyed and some will be retained (see Fig. 2).

From the geometry of the f.c.c. lattice it follows that for a single dislocation on the 111 plane, $1 / 3$ of the A-B nearest neighbour pairs will remain nearest neighbours. The passing through of a dislocation can also create $A-B$ nearest neighbour pairs. The area density is given by $2 / 3 y_{A} x_{B}+x_{A} x_{B}$ $+2 / 3 y_{\mathrm{B}} x_{\mathrm{A}}+x_{\mathrm{A}} x_{\mathrm{B}}=2 / 3 y_{\mathrm{A}} x_{\mathrm{B}}+2 / 3 y_{\mathrm{B}} x_{\mathrm{A}}+2 x_{\mathrm{A}} x_{\mathrm{B}}$. Thus the total area density of $\mathrm{A}-\mathrm{B}$ nearest neighbour bonds crossing the slip plane after passage of one dislocation is:

$$
\rho_{A-B}\left(n_{d}=1\right)=\frac{4}{\sqrt{3} b^{2}}\left[\frac{1}{3}\left(y_{A}+y_{B}\right)+\frac{2}{3} y_{A} x_{B}+\frac{2}{3} y_{B} x_{A}+2 x_{A} x_{B}\right]
$$

The change in area density of A-B nearest neighbour bonds crossing the slip plane on passing of one dislocation is

$$
\begin{aligned}
& \rho_{A-B}\left(n_{d}=0\right)-\rho_{A-B}\left(n_{d}=1\right)=\frac{4}{\sqrt{3} b^{2}}\left[\frac{2}{3}\left(y_{A}+y_{B}\right)-\left(\frac{2}{3} y_{A} x_{B}+\frac{2}{3} y_{B} x_{A}+2 x_{A} x_{B}\right)\right] \\
& \cong \frac{4}{\sqrt{3} b^{2}} \frac{2}{3}\left(y_{A}+y_{B}\right)
\end{aligned}
$$

where the approximation is valid for dilute alloys. Passage of further dislocations will cause further changes in area density of A-B nearest neighbour bonds crossing the slip plane. As the magnitude of these changes will decrease on passing of each further dislocation, the first dislocation experiences the greatest resistance. Considering in approximation that the energy related to coclusters is defined by the enthalpy of the nearest neighbour bond $\Delta H_{\mathrm{A}-\mathrm{B}}$ we can approximate: 


$$
\begin{aligned}
& \Delta \tau_{s r o}=\frac{\gamma_{s r o}}{b}=\frac{\Delta H_{A-B}}{b}\left[\rho_{A-B}\left(n_{d}=0\right)-\rho_{A-B}\left(n_{d}=1\right)\right] \\
& =\frac{\Delta H_{A-B}}{b^{3}} \frac{4}{\sqrt{3}}\left[\frac{2}{3}\left(y_{A}+y_{B}\right)-\left(\frac{2}{3} y_{A} x_{B}+\frac{2}{3} y_{B} x_{A}+2 x_{A} x_{B}\right)\right]
\end{aligned}
$$
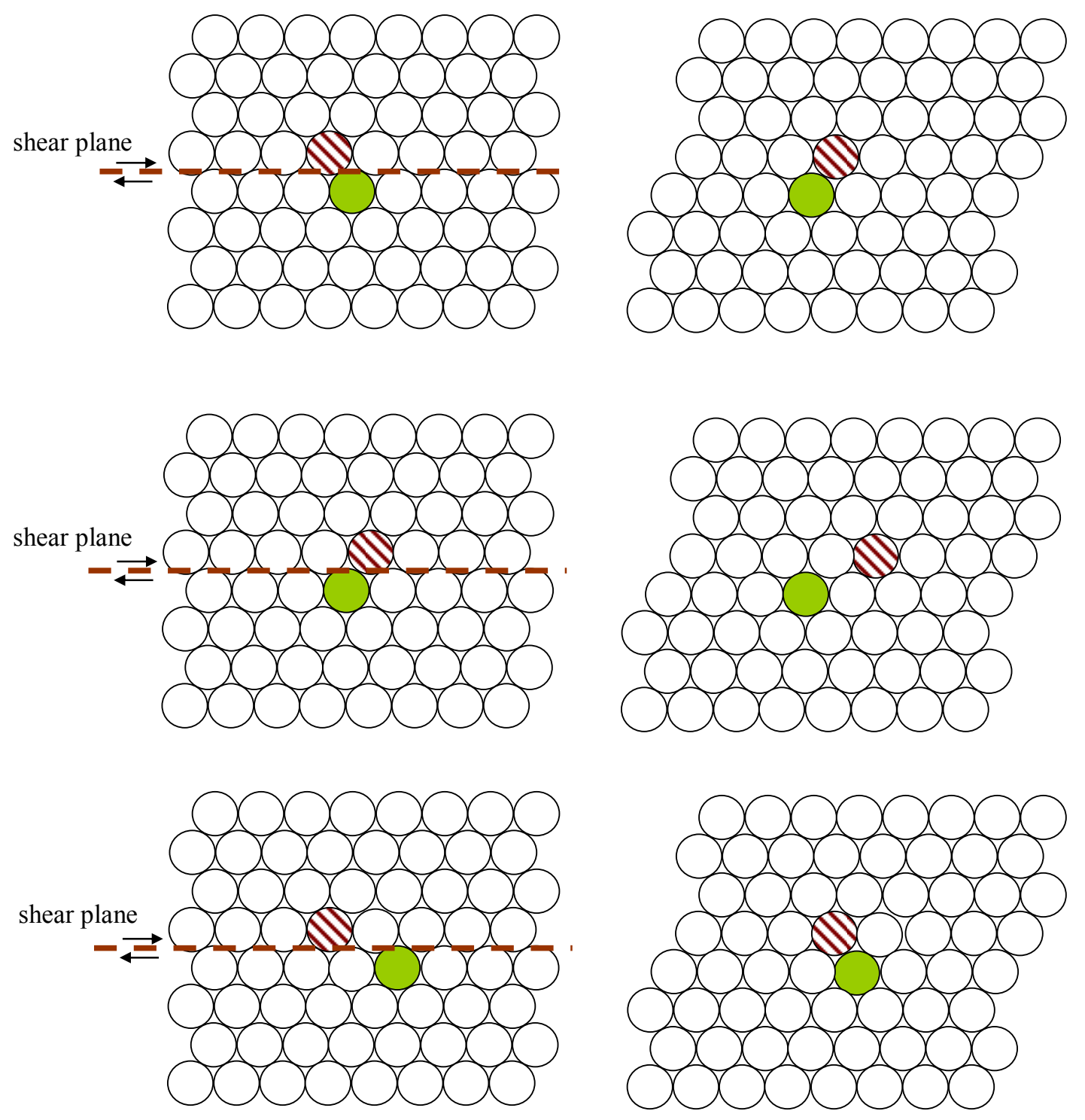

Fig. 2 A 111 plane in an FCC lattice with a 2 atom co-cluster being cut by a dislocation. Top shows before and after with the co-cluster remaining intact in a rotated form; middle shows before and after with the co-cluster being eliminated, which requires an energy input; and bottom shows before and after in the case where the passing of one dislocation creates a co-cluster, which releases energy. 
Modulus hardening

Modulus hardening is a strengthening mechanism that is difficult to deal with theoretically [28], leading to quite complex expressions. The very much simplified treatment by Cartaud et al [37] (see also Ref. [38]), which has been adopted in a range of works, approximates the strengthening due to difference in shear modulus as:

$$
\Delta \tau_{\mathrm{m}}=\frac{\Delta \mu}{4 \pi \sqrt{2}} \sqrt{f^{\mathrm{cl}}}
$$

where $f^{\mathrm{cl}}$ is the volume fraction of the clusters and $\Delta \mu$ is the difference in shear modulus between zones, $\mu_{c l}$, and surrounding metallic phase. In the works that apply the latter equation, $\mu_{c l}$ has invariably been determined by fitting to strength data. A more realistic way of obtaining $\mu_{c l}$ is by approximating it as a weighted average of the moduli of the individual pure substances, i.e. for an $\mathrm{M}_{\mathrm{m}} \mathrm{A}_{\mathrm{a}} \mathrm{B}_{\mathrm{b}}$ cluster:

$$
\mu_{c l}=\frac{m \mu_{M}+a \mu_{A}+b \mu_{B}}{m+a+b}
$$

For example, for larger clusters in $\mathrm{Al}-\mathrm{Cu}-\mathrm{Mg}$, where $\mathrm{Cu}, \mathrm{Mg}$ and $\mathrm{Al}$ content may be tending towards the composition of $\mathrm{S}$ (i.e. $25 \% \mathrm{Cu}, 25 \% \mathrm{Mg}$ and $50 \% \mathrm{Al}$ ) the above equation gives an estimation of $\mu_{c l}$, of $30 \mathrm{GPa}$ (using $\mu_{A l}=26.2 \mathrm{GPa}, \mu_{C u}=48.3 \mathrm{GPa}$ and $\mu_{M g}=17.3 \mathrm{GPa}$ from [39]).

A more detailed approximation of the modulus hardening can be obtained by a calculation of the interaction forces of screw and edge dislocations (including the maximum interaction force $F_{\mathrm{o}}$ ) as they pass through the area (precipitate) with differing modulus. This type of calculation has been performed by Nembach [40] for a spherical precipitate and various models of the dislocation. Based on Friedel's approximation:

$$
\Delta \tau=1.4 \frac{F_{o}^{3 / 2} f^{1 / 2}}{r b(2 \pi S)^{1 / 2}}
$$

Nembach's analysis [40] showed that the critical shear stress due to modulus hardening can be represented as:

$$
\Delta \tau_{m}=1.4 \alpha^{3 / 2} \Delta \mu^{3 / 2} f^{1 / 2} b\left(\frac{r_{p}}{b}\right)^{3 / / 2-1}(2 \pi S)^{-1 / 2}
$$

where $S$ is the dislocation line tension, and $\alpha$ and $\beta$ are parameters that are obtained from the dislocation precipitate interaction models. As different dislocation core models predict somewhat different interaction forces between dislocation and precipitate, some uncertainty in $\Delta \tau_{\mathrm{m}}$ results. Averaged values are obtained for $\alpha=0.096$ and $\beta=0.76$, respectively.

\section{Chemical hardening}

Chemical hardening, in its classical meaning, is due to the interfacial energy between precipitate and matrix, and strength increments a linearly proportional to this interfacial energy. It is 
conceptually difficult to relate a cluster (even a dimer) to an interfacial energy. As an estimate of $\Delta \tau_{\text {ch }}$ we considered the classical expression for chemical hardening and the value for the interfacial energy provided in [7]. This predicts $\Delta \tau_{\mathrm{ch}} \sim 0.03 \Delta \tau_{\text {sro }}$, i.e. $\Delta \tau_{\mathrm{ch}}$ is virtually negligible.

\section{Experimental}

The compositions of the alloys studied are presented in Table 1 . Alloy 1 was produced as sheet through casting, homogenising, hot rolling in several passes, solution treatment at $500^{\circ} \mathrm{C}$ and subsequent cold deformation through cold rolling to 5 or $10 \%$. This alloy was aged for 2,7 or 21 days at $170^{\circ} \mathrm{C}$.

$\begin{array}{lllllll}\text { Alloy } & \mathrm{Cu} & \mathrm{Mg} & \mathrm{Mn} & \mathrm{Si} & \mathrm{Fe} & \mathrm{Cu} / \mathrm{Mg} \\ \text { Alloy 1: Al-1.3Mg-0.07Cu-0.4Mn } & 0.07 & 1.34 & 0.44 & 0.19 & 0.19 & 0.05 \\ \text { Alloy 2a: Al-3Mg-0.2Cu-0.1Mn } & 0.18 & 3.16 & 0.12 & 0.12 & 0.10 & 0.06 \\ \text { Alloy 2b: Al-3Mg-0.2Cu-0.1Mn } & 0.17 & 3.09 & 0.12 & 0.14 & 0.09 & 0.06 \\ \text { Alloy 3: Al-1.2Mg-1.2Cu-0.2Mn } & 1.19 & 1.19 & 0.20 & 0.03 & 0.02 & 1.00 \\ \text { Alloy 4: Al-1.5Mg-1.8Cu-0.2Mn } & 1.82 & 1.49 & 0.20 & 0.02 & 0.02 & 1.22\end{array}$

Table 1 Chemical composition of alloys (at $\%)$

Alloy $2 \mathrm{a}$ and $2 \mathrm{~b}$ are different batches of plate with identical target composition. Alloy 2a was solution heat treated at $550^{\circ} \mathrm{C}$ for $30 \mathrm{~min}$, and subsequently quenched. Ageing was carried out at $180^{\circ} \mathrm{C}$ for a range of times between 1 and $8 \mathrm{~h}$. DSC samples were prepared from the heat treated samples. Alloy $2 \mathrm{~b}$ was produced through casting, followed by hot and cold rolling (see $[41,42]$ ). DSC samples of alloy $2 \mathrm{~b}$ were resolution treated at $460^{\circ} \mathrm{C}$ and aged at 140 and $160^{\circ} \mathrm{C}$.

Alloys 3 and 4 were produced as hot rolled plate. DSC samples were re-solution treated at $495^{\circ} \mathrm{C}$ for $30 \mathrm{~min}$, quenched into room temperature water, weighed and introduced into the calorimeter. DSC runs started three minutes after the quenching.

All DSC samples were disc shaped (5 mm diameter, approximately $1 \mathrm{~mm}$ thick). DSC measurements were performed using a Perkin-Elmer calorimeter Pyris 1 DSC, with pure nitrogen purge gas as protective gas atmosphere. Heating rates from 2.5 to $150^{\circ} \mathrm{C} / \mathrm{min}$ was used. The calorimeter was calibrated with an Indium standard at all block temperatures used (-30, -50, -100 and $\left.-140^{\circ} \mathrm{C}\right)$. All DSC traces were corrected by subtracting a baseline obtained from a DSC run with empty aluminium pans. Further corrections for imperfections of the DSC as well as correction for the heat capacity contribution not related to reactions of the samples is needed [43]. The optimum choice for this correction is alloy dependent and was considered in [44]. For the Cu-lean 
alloys 1 and 2, further correction was achieved by subtracting a linear function of $T$ fitted to the initial part of the curve, where no reactions are thought to occur. Alloys 3 and 4 were further corrected by a second order polynomial which described the combined effect of heat capacity difference of the sample and reference and baseline fluctuations. The coefficients of the second order polynomial were fitted by assuming that the heat effects due to reactions were zero at the following three points: (1) at the initial part of the curves where no reaction occurs; (2) at the completion of the S dissolution effect; and (3) at the point where the precipitation effect of the clusters ends and the dissolution effect of the clusters starts. Thus all DSC curves presented represent heat flows caused by reactions, which are directly related to enthalpy changes:

$$
\Delta H=\int_{T_{1}}^{T_{2}} c_{p} d T
$$

where $c_{\mathrm{p}}$ is the heat flow measured by the DSC (the heat capacity at constant pressure) between the selected temperatures $T_{1}$ and $T_{2}$. (Selected DSC data on alloys 3 and 4 is taken from [45])

Possible experimental error in the temperature determination in DSC experiments is mainly due to sample variability and instrument calibration. The overall accuracy is typically about 1 to $2^{\circ} \mathrm{C}$. The main source of inaccuracy for the determination of the part of $\Delta H$ due to reactions is the choice of the points in the baseline correction and to a lesser extend sample variability and instrument calibration. Typical accuracies are in the order of $3 \%$ or $0.2 \mathrm{~J} / \mathrm{g}$, whichever is the higher.

Course intermetallic phases (typically larger than 100nm) in Alloys 1-4 were studied in a Jeol 6500F Field Emission Gun Scanning Electron Microscope (FEG-SEM) equipped with Energy Dispersive Spectrometer (EDS) using mechanically ground and polished samples.

\section{Results and Analysis}

\section{Thermodynamic data}

As a result of the very low $\mathrm{Cu}$ content, DSC thermograms of alloy 1 generally showed very weak thermal effects. Samples aged for 2 days at $170^{\circ} \mathrm{C}$ show a small endothermic effect which peaks at $220^{\circ} \mathrm{C}$ (curves not presented). Due to the very low heat flows and slight baseline instability the DSC curves of alloy 2 aged at $180^{\circ} \mathrm{C}$ (Fig. 3) become progressively more erratic beyond about $250^{\circ} \mathrm{C}$. However up to about $250^{\circ} \mathrm{C}$ the DSC thermograms of alloy 2 are consistent and when aged for 4 to $48 \mathrm{~h}$ at $180^{\circ} \mathrm{C}$ the alloy, showed a substantial endothermic effect peaking at $230^{\circ} \mathrm{C}$. This effect is seen to develop gradually during ageing for 1,4 and $8 \mathrm{~h}$, reaching a maximum heat content after $8 \mathrm{~h}$. This gradual development of the endothermic effect relates to a gradual increase in $G$ of the samples on ageing. TEM data on the same alloy shows that after 4 and $8 \mathrm{~h}$ of ageing, coherent nanometer-sized needle and lath shaped particles are present [46,47]. After $1 \mathrm{~h}$ ageing these precipitates could not be detected in the TEM. At this stage of the ageing the DSC thermograms 
show a dissolution effect that peaks at about $210^{\circ} \mathrm{C}$, with a heat content that is substantially lower than that obtained after 4 and $8 \mathrm{~h}$.

DSC curves of the solution treated alloy $2 \mathrm{~B}$ aged at $140^{\circ} \mathrm{C}$ are presented in Fig. 4 . This data shows that in as quenched samples an exothermic reaction occurs at about 120 to $180^{\circ} \mathrm{C}$. When aged at $140^{\circ} \mathrm{C}$ this exothermic reaction disappears and the heat evolved in the endothermic reaction between $220^{\circ} \mathrm{C}$ and $270^{\circ} \mathrm{C}$ increases. The ageing treatments considered here are less severe than the 4 and $8 \mathrm{~h}$ of ageing at $180^{\circ} \mathrm{C}$ in which ordered nano-scale precipitates were detected in alloy 2 . Thus, these precipitates should not form during ageing at $140^{\circ} \mathrm{C}$. The effects observed in Fig. 4 are interpreted to be due to the formation of co-clusters at about 120 to $180^{\circ} \mathrm{C}$, whilst the endothermic effect is thought to be due to the dissolution of co-clusters with in the latter stages some transformation of co-clusters a phase with long range order, probably the rod/lath shaped particles observed by Kovarik et al [23].

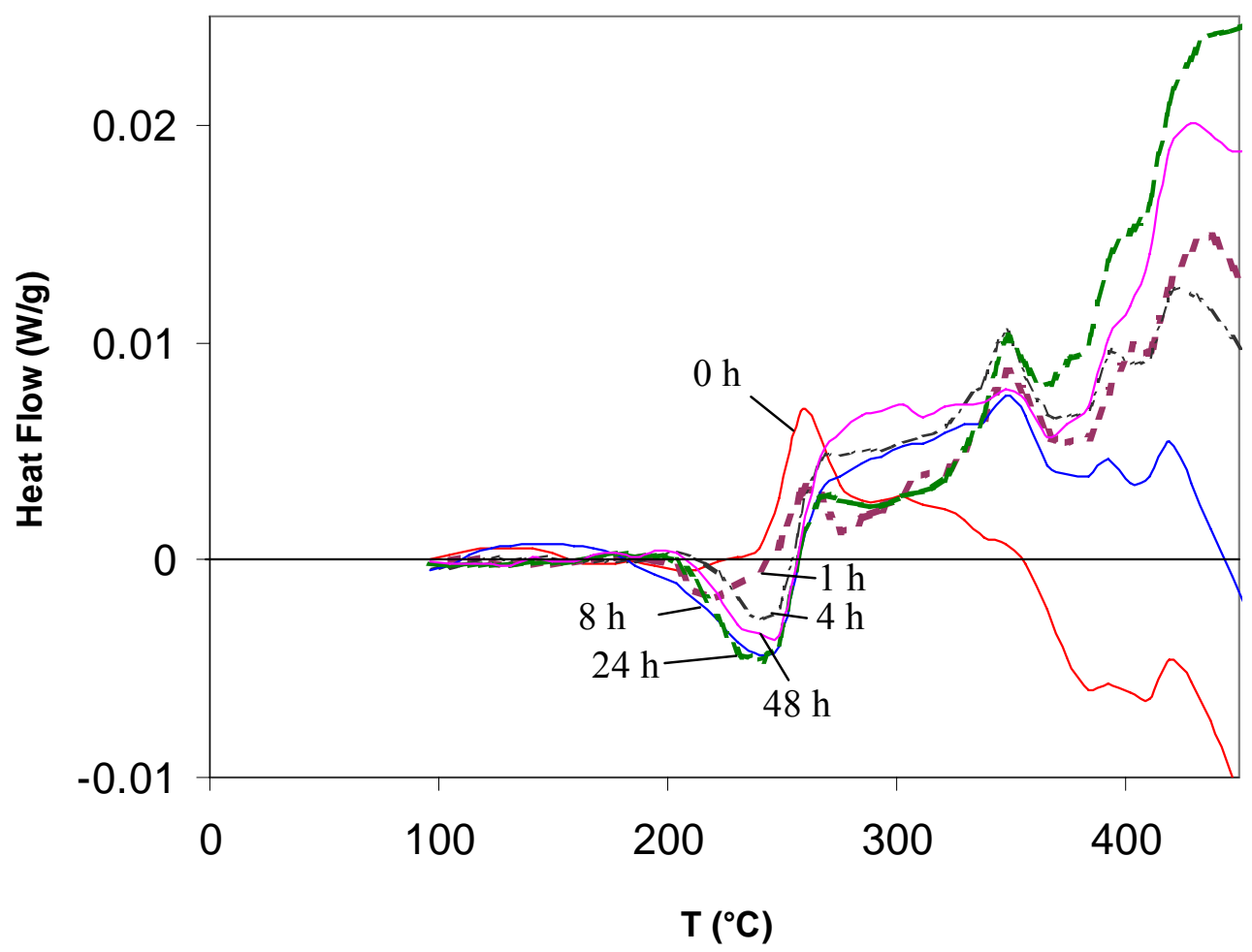

Fig. 3 DSC thermograms of solution treated alloy $2 \mathrm{Al}-3.2 \mathrm{Mg}-0.18 \mathrm{Cu}$ after ageing for $0,1,4,8$, 24 and $48 \mathrm{~h}$ at $180^{\circ} \mathrm{C}$.

DSC curves of the solution treated Al-1.2Mg-1.2Cu alloy (alloy 3) at different heating rates are presented in Fig. 5a. These thermograms show heat effects that have heat contents well in excess of those observed in alloy 1 and 2. Consistent with the well-known theory of thermally activated reactions [48], heat effects in these curves shift to higher temperatures with increasing heating rate. The end temperature of exothermic effect $\left(T_{e}\right)$, which also increases with temperature, reflects the stage at which the driving force for further reaction has decreased to zero [49]. This is the stage at 
which the average composition of solute atoms in the Al-rich phase has reached the metastable solvus. As $T_{e}$ increases with heating rate, and the solvus concentrations increase with temperature, the total heat contents of the exothermic effects decrease with increasing heating rate [50]. On ageing for up to $24 \mathrm{~h}$ at room temperature, the first exothermic effect in the DSC curves of the solution treated alloy $3(\mathrm{Al}-1.2 \mathrm{Cu}-1.2 \mathrm{Mg})$ gradually disappears. 3DAP analysis of these alloys presented elsewhere [7,51] shows that whilst immediately after quenching the $\mathrm{Mg}$ atoms are randomly distributed, $\mathrm{Mg}$ atoms become clustered, and from analysis of clusters that are larger than about 10 atoms, the formation of $\mathrm{Cu}-\mathrm{Mg}$ co-clusters is identified. No other phases can be identified, and hence the low temperature exothermic reaction is attributed to the formation of $\mathrm{Cu}-\mathrm{Mg}$ coclusters. DSC curves of the solution treated alloy $4(\mathrm{Al}-1.8 \mathrm{Cu}-1.5 \mathrm{Mg})$ at different heating rates are presented in Fig. 5b. These thermograms show heat effects at similar positions to those in alloy 3, whilst the heat contents of the effects are on average about $40 \%$ larger. 3DAP analysis similar to that described for alloy 3 indicated that also for alloy 4 the low temperature exothermic effect was due to the formation of $\mathrm{Cu}-\mathrm{Mg}$ co-clusters [7].

The measured heat contents of the effects and isothermal ageing temperatures for the alloys are presented in Table 2. A range of data on $\Delta Q\left(T_{e}\right)$ presented in the literature $[52,53,54]$ on a number of alloys is also included in this table.

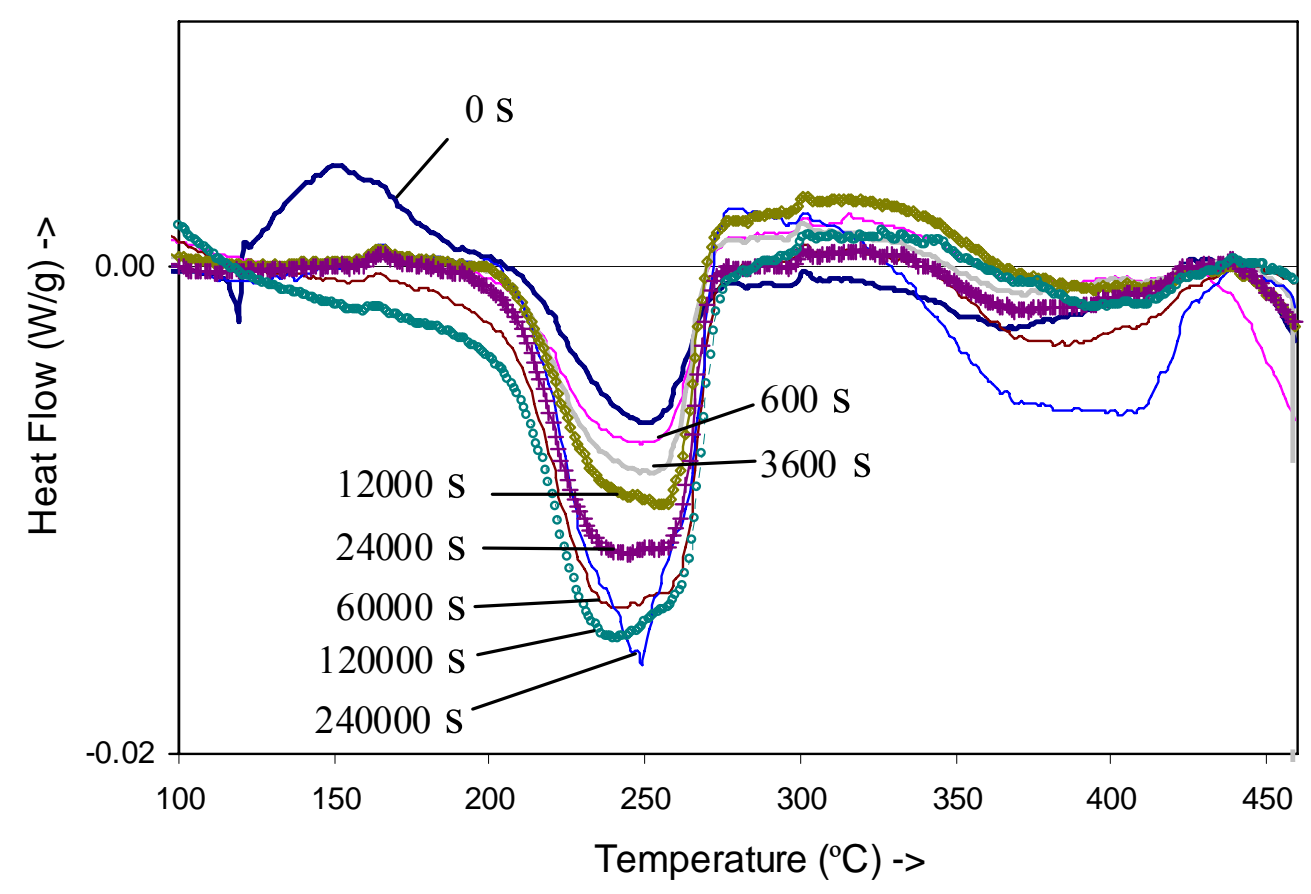

Fig. 4 DSC curves of the solution treated alloy 2B (Al-3.1Mg-0.17Cu) after solution treatment and after ageing for up to $240 \mathrm{ks}(60.7 \mathrm{~h})$ at $140^{\circ} \mathrm{C}$. 


\begin{tabular}{lllllrrr} 
Experiment & \multicolumn{1}{c}{ Reference } & \multicolumn{1}{c}{$x_{C u}^{g}$} & \multicolumn{1}{l}{$x_{M g}^{g}$} & \multicolumn{1}{l}{$x_{M n}^{g}$} & $T_{\mathrm{e}}\left({ }^{\circ} \mathrm{C}\right)$ & $\Delta Q(\mathrm{~J} / \mathrm{g})$ & \multicolumn{1}{c}{$\Delta Q(\mathrm{~J} / \mathrm{g})$} \\
& & & & & & measured & predicted \\
& & & & & & \\
IC & Zahra et al [52] & 0.0025 & 0.047 & 0.0007 & 60 & 3.5 & 3.15 \\
DSC exo & Verlinden \& Zahra [53] & 0.0025 & 0.047 & 0.0007 & 195 & 2.9 & 2.72 \\
IC & Zahra et al [52] & 0.0023 & 0.033 & 0.0004 & 60 & 3.5 & 2.89 \\
IC & Zahra et al [52] & 0.0040 & 0.033 & 0.0008 & 60 & 6 & 5.04 \\
DSC exo & Verlinden \& Zahra[53] & 0.0040 & 0.033 & 0.0008 & 180 & 4.4 & 4.56 \\
IC & Zahra et al [52] & 0.0090 & 0.014 & 0.0000 & 30 & 11.7 & 11.4 \\
IC & Zahra et al [52] & 0.0110 & 0.017 & 0.0000 & 30 & 13.5 & 13.9 \\
DSC exo & This work & 0.0007 & 0.013 & 0.0000 & 170 & 0.2 & 0 \\
DSC exo & This work & 0.0007 & 0.013 & 0.0000 & 170 & 0 & 0 \\
IC & Zahra et al [52] & 0.0025 & 0.047 & 0.0007 & 0 & 0 & 3.16 \\
IC & Verlinden \& Zahra [53] & 0.0040 & 0.033 & 0.0008 & 0 & 0 & 5.06 \\
DSC exo & Charai et al [54] & 0.0087 & 0.014 & 0.0000 & 150 & 9.4 & 9.81 \\
DSC exo & Charai et al [54] & 0.0090 & 0.015 & 0.0000 & 165 & 9.3 & 9.77 \\
DSC exo & This work & 0.0121 & 0.012 & 0.0020 & 111 & 14.1 & 12.5 \\
DSC endo & This work & 0.0018 & 0.030 & 0.0000 & 180 & 2 & 1.74 \\
DSC & This work & 0.0018 & 0.030 & 0.0000 & 215 & 0 & 0.00 \\
DSC endo & This work & 0.0018 & 0.030 & 0.0000 & 180 & 0.5 & 0.00 \\
DSC endo & This work & 0.0017 & 0.032 & 0.0012 & 140 & 2.0 & 1.95 \\
DSC endo & This work & 0.0017 & 0.032 & 0.0012 & 200 & 0.7 & 1.45
\end{tabular}

Table 2 Magnitude of the heat contents of exothermic precipitation effect and heat contents of endothermic dissolution effect $(\Delta Q)$ with gross compositions $\left(x_{C u}^{g}, x_{M g}^{g}, x_{M n}^{g}\right)$. In the first column 'DSC exo' stands for an exothermic effect observed in a linear heating experiment, 'DSC endo' stands for an endothermic effect observed in a linear heating experiment, IC stands for an exothermic effect observed in an isothermal calorimetry experiment. $T_{\mathrm{e}}$ stands for the end temperature of the exothermic effect in a 'DSC exo' experiment, or the ageing temperature in a 'DSC endo' experiment, or the isothermal ageing temperature during the IC experiment.

\section{Comparing thermodynamic data with the model}

To compare the measured $\Delta Q$ data with the regular solution model for dimers, model predictions were made using Eqs. 1-3 with Eqs. 7-9. In order to achieve these model predictions we first needed to determine $\Delta H_{\mathrm{A}-\mathrm{B}}$. From each data line in Table 2 a value of $\Delta H_{\mathrm{A}-\mathrm{B}}$ can be obtained, we take $\Delta H_{\mathrm{A}-}$ $\mathrm{B}$ as the average from the experiments that are expected to yield the highest accuracy: DSC experiments at $5-40^{\circ} \mathrm{C} / \mathrm{min}$ for the alloy with the highest $\mathrm{x}_{\mathrm{Cu}}+\mathrm{x}_{\mathrm{Mg}}$. This provides $\Delta H_{\mathrm{A}-\mathrm{B}}=$ $34.5 \pm 0.5 \mathrm{~kJ} / \mathrm{mol}$. The predicted $\Delta Q$ values are presented in Table 2 and graph of predicted vs measured values of $\Delta Q$ considering all reactions which completed within 20 min for $T_{e}>100^{\circ} \mathrm{C}$ and completed within 7 days for $T_{e} \leq 60^{\circ} \mathrm{C}$ is provided in Fig. 6. Plots of $\Delta Q$ vs $T_{e}$ for alloys 3 and 4 are provided in Fig. 7. The correspondence between the regular solution model for dimers and the thermodynamic data obtained from calorimetry is excellent for all alloys. 

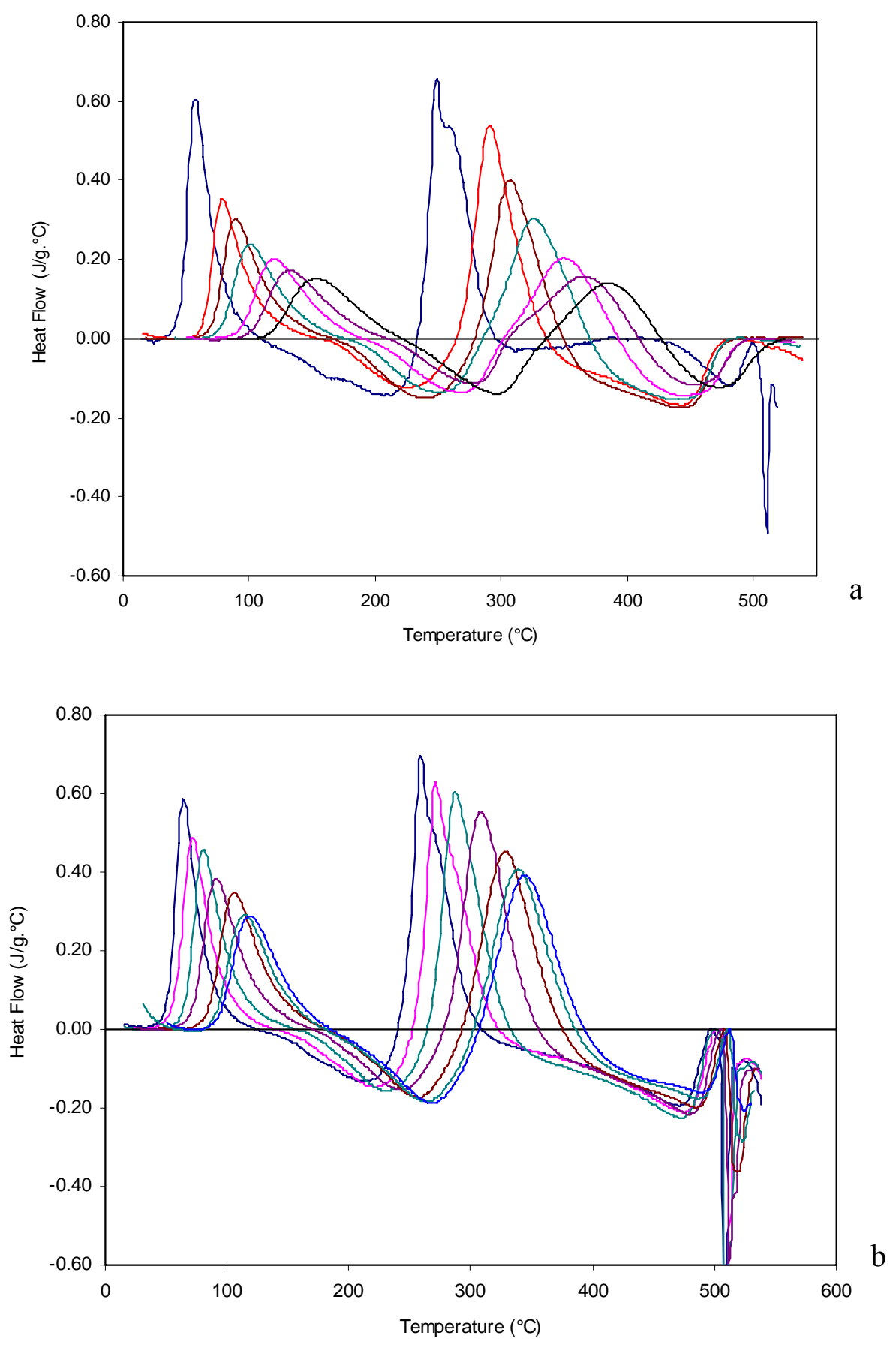

Fig. 5 DSC curves of a) the solution treated alloy 3 (Al-1.2Cu-1.2Mg) at (from left to right) heating rates $2.5,10,20,40,80,120$ to $150 \mathrm{~K} / \mathrm{min}$; and b) the solution treated alloy 4 (Al-1.8Cu$1.5 \mathrm{Mg}$ ) at (from left to right) heating rates $5,10,20,40,80,100$ and $120 \mathrm{~K} / \mathrm{min}$.

The validity of the thermodynamic model was further checked by comparing predictions for $\Delta Q$ using the more general equation Eq. 5 and optimising $a, \Delta H_{\mathrm{MmAaBb}}$ and $C$ ( $b$ is fixed at 1 , this is not a limitation as there are only 3 independent parameters). Best fits were obtained with $a$ close to 1 , which confirms that clusters have $\mathrm{Cu}: \mathrm{Mg}$ ratios close to 1 . Solvus predictions with optimised $a, \Delta H_{\mathrm{c}}$ 
and $C$ for the alloys were within about $2{ }^{\circ} \mathrm{C}$ of the one obtained with the regular solution model for dimers.

Additional DSC experiments were performed on two alloys that are right at the limit of stability of co-clusters at typical formation temperatures: $\mathrm{Al}-0.08 \mathrm{Cu}-1 \mathrm{Mg}(\mathrm{at} \%)$ and $\mathrm{Al}-0.08 \mathrm{Cu}-2 \mathrm{Mg}($ at $\%$ ). For these alloys predicted heat evolution are 0 and $0.4 \mathrm{~J} / \mathrm{g}$, respectively. Observed heat of dissolution of co-clusters are right at the detection limit, at $0.2 \pm 0.2 \mathrm{~J} / \mathrm{g}$ averaged for the two alloys. These observations should be compared with the data for alloy $2 b$, for which co-cluster formation and dissolution was readily observed. Thus, these observations provide further support for the model predictions on stability limits of co-clusters for these alloys with very low $\mathrm{Cu}$ content.

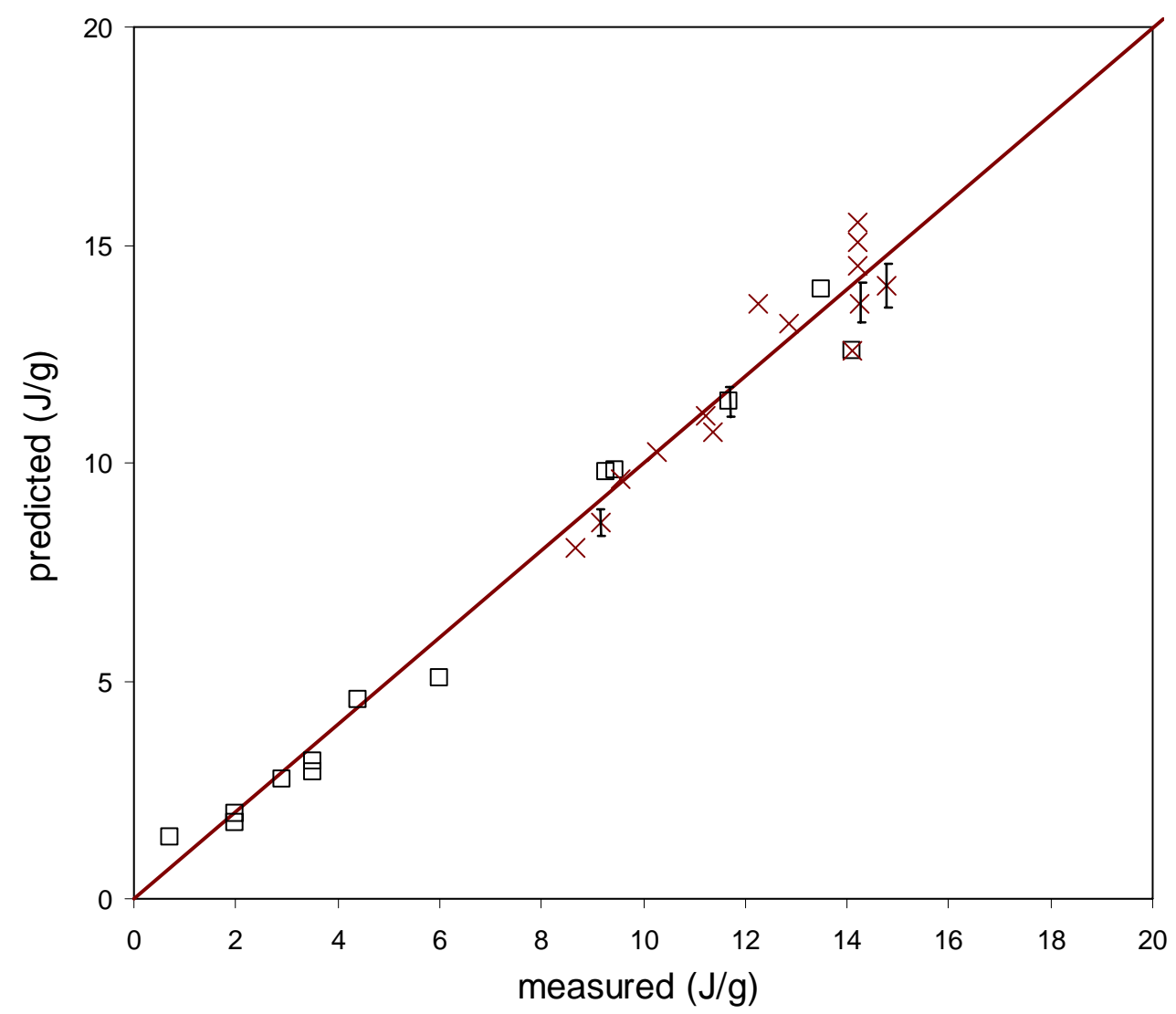

Fig. 6 Measured vs. predicted $\Delta Q$ from calorimetry experiments for a range of Al-Cu-Mg alloys. $\mathrm{a}=1, \Delta H_{\mathrm{c}}=34.5 \mathrm{~kJ} / \mathrm{mol} . \times$ : DSC data on alloys 3 and $4 ; \square:$ all other data.

Considering the typical measurement error, the level of agreement between calorimetry data and predictions of the thermodynamics based on a regular solution model in Fig. 6 and Fig. 7 is excellent. These figures contain thermodynamic data for a wide range of alloys for the full range of temperatures at which co-cluster formation is normally observed $\left(20\right.$ to $200^{\circ} \mathrm{C}$ ). To prove the regular solution model is not just a fortuitous fit but physically realistic, we will show in the Discussion section that the present interpretation is consistent with published microstructural data. 


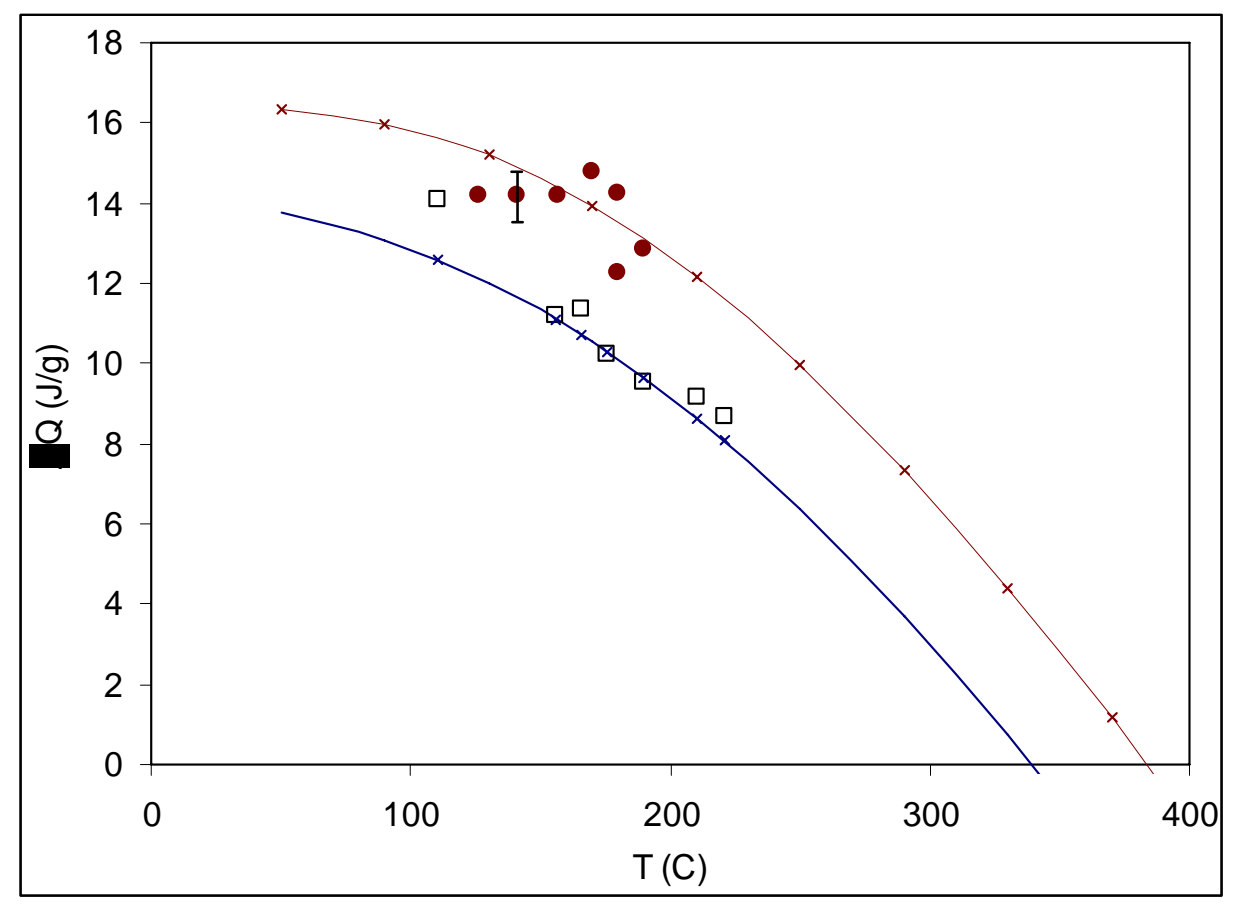

Fig. 7 Measured $\Delta \mathrm{Q}$ (symbols) and predicted $\Delta \mathrm{Q}$ (lines) as a function of end temperature for alloys 3 and $4 . a=1, \Delta H_{\mathrm{c}}=34.5 \mathrm{~kJ} / \mathrm{mol}$.

\section{Strength and hardness data}

The yield strength of an alloy that contains co-clusters is dominated by the contribution due to clusters, with further minor contributions due to grain boundaries, dislocations and solute in the Al rich phase. A general approximation of the superposition of strengthening mechanisms is [55]:

$$
\begin{aligned}
\sigma_{y} & =\sigma_{g b}+M\left(\tau_{s o l}+\tau_{d}+\tau_{c l}\right) \\
& =\sigma_{g b}+M\left(\tau_{s o l}+\tau_{d}+\left(\Delta \tau_{s r o}+\Delta \tau_{m}+\Delta \tau_{c h}\right)\right)
\end{aligned}
$$

where $\sigma_{\mathrm{gb}}$ is the contribution due to grain boundaries $\tau_{\mathrm{d}}$ is due to stored dislocations (introduced by working) and $\tau_{\mathrm{sol}}$ is due to dissolved elements. The method for obtaining $\sigma_{\mathrm{gb}}$ is outlined in [55], it provides $\sigma_{\mathrm{gb}}$ values that are less than $1 \mathrm{MPa}$ for the relatively coarse grained alloys considered here. In the alloys considered, $\tau_{\mathrm{d}}$ is zero for solution treated and aged alloys and for T351 (solution treated stretched and aged alloys) it is obtained from the model outlined in [56], which provides $\tau_{\mathrm{d}}$ values of about $5 \mathrm{MPa}$. $\tau_{\text {sol }}$ is obtained form the model outlined in [57]. To verify the model we will compare yield strength predictions with data for a range of solution treated and subsequently aged Al-Cu-Mg alloys. (Strength of rolled Al-Cu-Mg alloys is anisotropic. Where available we will use the average of L and LT tests; if only L is available we will consider that the average of $\mathrm{L}$ and LT yield strengths, $\sigma_{\mathrm{y}, \mathrm{L}}$ and $\sigma_{\mathrm{y}, \mathrm{LT}}$, is about $0.95 \sigma_{\mathrm{y}, \mathrm{LT}}$ [58].) The results, presented in Table 3 , show a very good correspondence: the typical accuracy (root mean square error) is $11 \mathrm{MPa}$ for data ranging from 110 to $350 \mathrm{MPa}$. This limited level of deviations is thought to be mostly due to small uncertainties not related to the present strength model that include uncertainties in alloy 
composition (a $0.1 \mathrm{wt} \%$ change in $\mathrm{Cu}$ content causes $6 \mathrm{MPa}$ change in predicted $\sigma_{\mathrm{y}}$ ), limited measurements inaccuracies and the anisotropy of yield strength introduced by texture of rolled alloys.

$\begin{array}{cccccl}x_{\mathrm{Cu}}^{g} & \begin{array}{c}x_{M g}^{g} \\ \text { (at) }\end{array} & \begin{array}{c}\sigma_{\mathrm{y}} \\ \text { measured } \\ (\mathrm{MPa})\end{array} & \begin{array}{c}\sigma_{\mathrm{y}} \\ \text { modelled } \\ (\mathrm{MPa})\end{array} & \begin{array}{c}T \\ \left({ }^{\circ} \mathrm{C}\right)\end{array} & \text { Ref } \\ 0.0179 & 0.0139 & 315 & 295 & 25 & \text { This work } \\ 0.0119 & 0.0117 & 265 & 273 & 25 & \text { This work } \\ 0.0106 & 0.0160 & 250 & 262 & 30 & \text { Wil [59] } \\ 0.0106 & 0.0128 & 255 & 258 & 20 & \text { Pol [60] } \\ 0.0050 & 0.0170 & 150 & 148 & 150 & \text { Rav [61] } \\ 0.0080 & 0.0170 & 200 & 204 & 150 & \text { Rav [61] } \\ 0.0110 & 0.0170 & 245 & 246 & 180 & \text { Rav [61] } \\ 0.0187^{*} & 0.0160^{\star} & 325 & 343^{*} & 25 & \text { ASM [63] } \\ 0.0183 & 0.0148 & 348 & 346 & 25 & \text { Sri [64] } \\ 0.0179 & 0.0145 & 328 & 316 & 25 & \text { This work } \\ 0.0025 & 0.0450 & 130 & 140 & 180 & \text { Rat [65] } \\ 0.0024 & 0.0320 & 95 & 114 & 180 & \text { Cou [66] } \\ 0.0022 & 0.0427 & 112 & 126 & 180 & \text { Cou [66] } \\ 0.0169 & 0.0108 & 277 & 289 & 25 & \text { Fin [67] }\end{array}$

* The median 2024 composition with $0.1 \mathrm{wt} \% \mathrm{Fe}$ is assumed.

Table 3 Predicted and measured yield strengths of various solution treated and subsequently aged Al-Cu-Mg alloys. Ageing is conducted to a state where co-cluster formation is completed: 4 to 10 days at $25^{\circ} \mathrm{C}$ and about $5 \mathrm{~min}$ at 150 and $180^{\circ} \mathrm{C}$. Data obtained for this work and from [59] Wil, [60] Pol, [61,62] Rav, [63] ASM, [64] Sri, [65] Rat, [66] Cou, and [67] Fin.

\section{Discussion}

Comparison of the thermodynamic model for dimers (regular solution model) and the strength model with calorimetry and yield strength data of well over a dozen $\mathrm{Al}-\mathrm{Cu}-\mathrm{Mg}$ alloys spreading over a wide range of compositions shows an excellent correspondence, with any remaining deviations likely to be mainly (or exclusively) caused by limited experimental errors. This has been achieved through determining just one parameter $\Delta H_{\mathrm{A}-\mathrm{B}}$. For other alloy systems that may contain co-cluster no consistent set of calorimetry and strength data could be found and hence, at present, we can not test the models for other alloys. However it appears clear from the present model that for a range of ternary or higher order alloys that are processed though a supersaturated solid solution involving two or more alloying elements decomposition will progress through a co-cluster stage. In the following we will focus our discussion on co-clusters in the $\mathrm{Al}-\mathrm{Cu}-\mathrm{Mg}$ system.

In the following discussion we will first discuss possible variants of the thermodynamic model, cluster size and cluster composition. Secondly, we will aim to show that all published microstructural data and quantum mechanic modelling is consistent with the present models. Thirdly we will consider possible other strengthening models. And finally we will show how the models can quantitatively explain the phenomenon of secondary ageing in Al-Li-Cu-Mg alloys. 


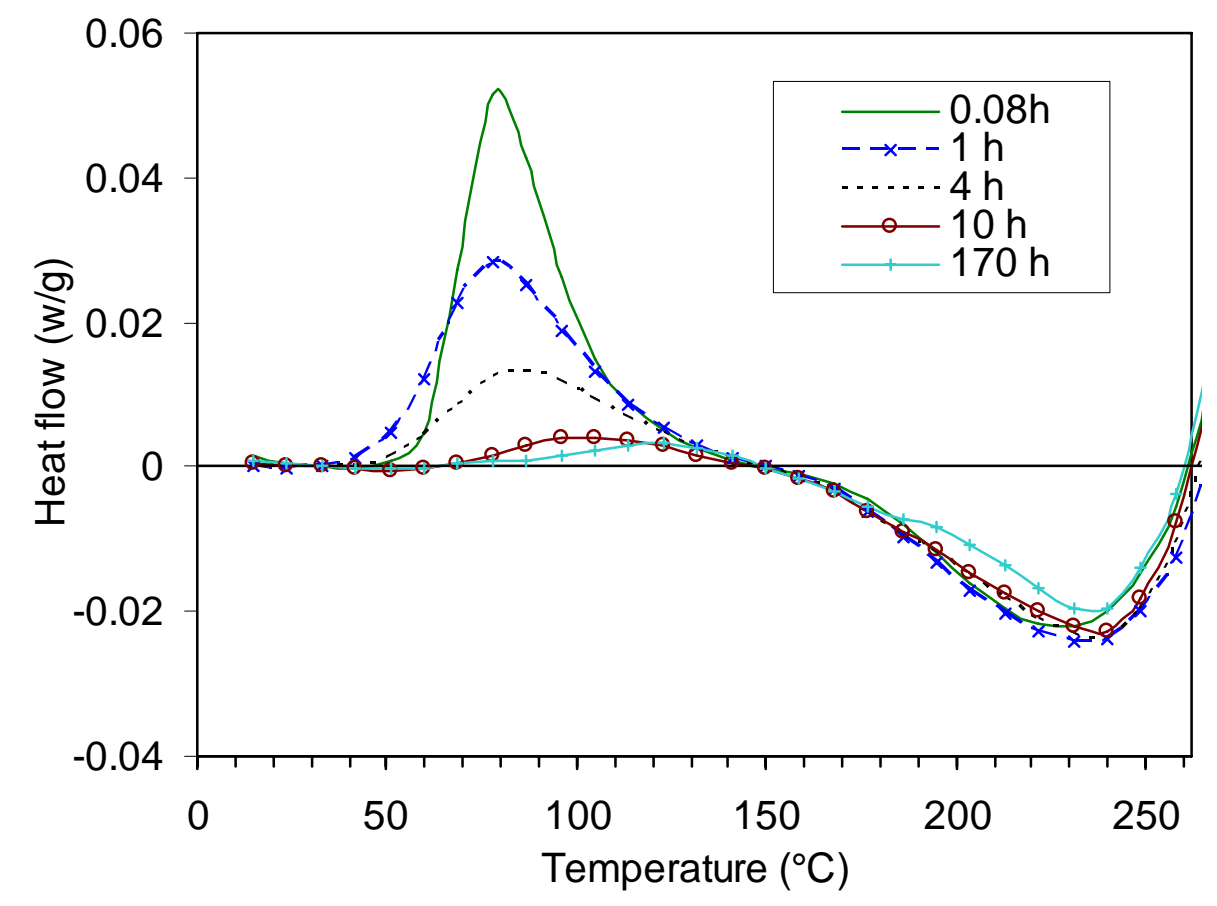

Fig. 8 DSC thermograms for quenched and subsequently room temperature aged $\mathrm{Al}-1.2 \mathrm{at} \% \mathrm{Cu}-$ $1.2 \mathrm{at} \% \mathrm{Mg}$ alloy. Depicted are thermograms after ageing times of (in order of decreasing exothermic heat effect) $0.08,1,4,10$ and $170 \mathrm{~h}$.

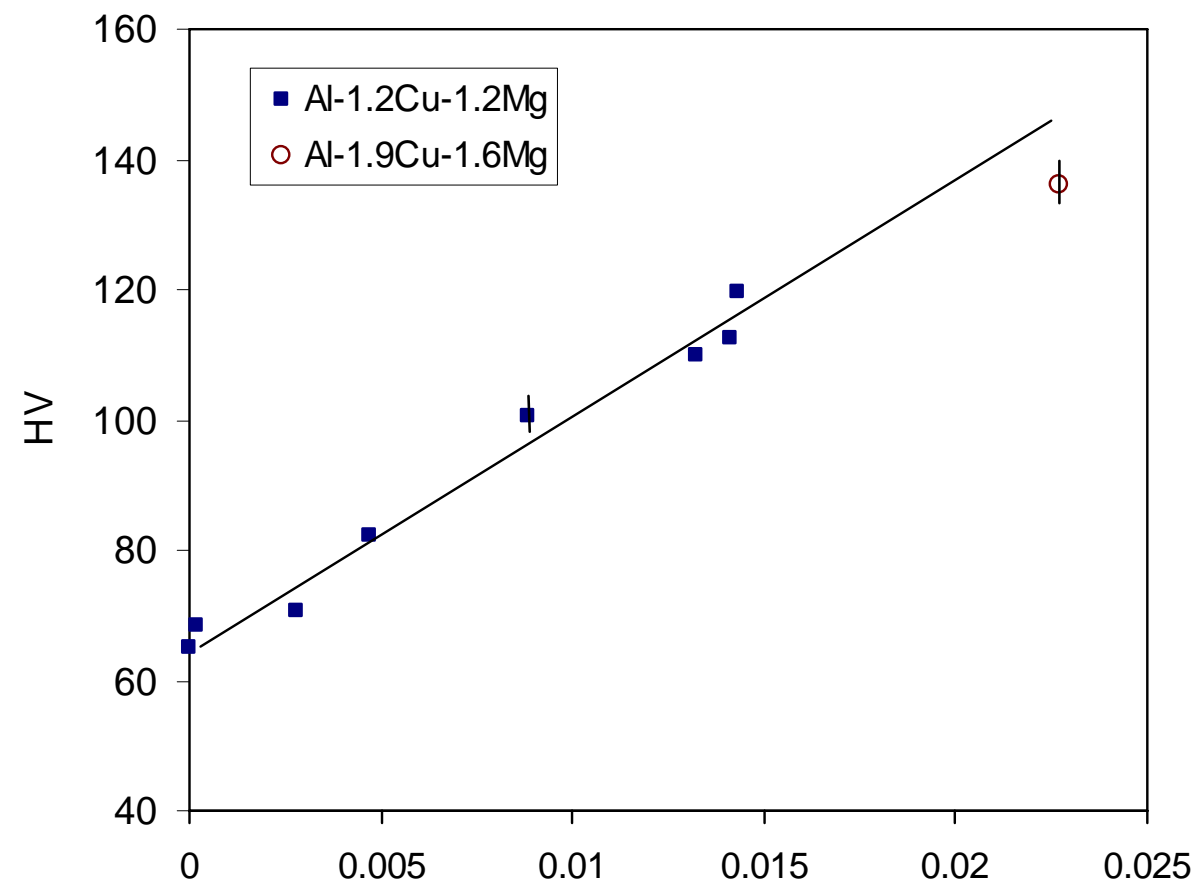

Fig. 9 Measured Vickers hardness vs the fraction of $\mathrm{Cu}$ and $\mathrm{Mg}$ atoms in co-clusters (for $\left.\Delta H_{\mathrm{c}}=34.5 \mathrm{~kJ} / \mathrm{mol}\right)$. 


\section{Cluster composition and further evolution}

As the fitting of the broader thermodynamic model (Eq. 5) provides $a: b=1$, the basic unit element of the co-cluster is $\mathrm{Cu}_{1} \mathrm{Mg}_{1} \mathrm{Al}_{\mathrm{p}}$ or multiples of these. In terms of the regular solution model this leaves open various possibilities, for instance complexes of $2 \mathrm{Cu}$ atoms with $2 \mathrm{Mg}$ atoms, with the $\mathrm{Cu}$ and $\mathrm{Mg}$ atoms not situated as nearest neighbours but separated by a certain number of $\mathrm{Al}$ atoms. Examples are given in Fig. 1. However, the excellent correspondence of the thermodynamic model for dimers and the strengthening model for dimers indicates that the main reaction involves the formation of the $\mathrm{Cu}-\mathrm{Mg}$ dimers: one $\mathrm{Cu}$ and one $\mathrm{Mg}$ atom in nearest neighbour positions. However this in itself does not exclude the possibility of larger co-clusters; and in fact all co-cluster constellations where $\Delta H$ for co-cluster formation is essentially related to a chain of bonds such as illustrated in Fig. 1 is consistent with the measured enthalpy changes and strength data. Isothermal calorimetry data shows that exothermic heat evolution during room temperature hardening peaks during the hardening, and reduces to zero by the time the hardness stabilises after about $48 \mathrm{~h}$ at room temperature. The latter, whilst consistent with the present models for dimers as well as extended chains where $\Delta H$ for co-cluster formation is essentially related to a chain of bonds, also indicates that any further growth of co-clusters does not have a significant impact on the enthalpy of the alloy. Hence, the occasional occurrence of larger co-clusters (larger than 10 atoms, in some cases larger than 100 atoms) should be considered as a coagulation of smaller co-clusters; with the coagulation not influencing the strength or $\Delta H$ to a significant extend. In these coagulated dimers some relaxation of the atomic positions will occur and the model for a needle/lath like phase appearing after $24-96 \mathrm{~h}$ at $180^{\circ} \mathrm{C}$ [23] can in fact be considered as a coagulation of dimers like in Fig. 1c with some relaxation of atoms positions.

\section{Nanostructure data and quantum mechanical modelling}

Whilst atom probe analysis can not show the existence of individual dimers, data is fully consistent with the above model. In particular, APFIM on Al-Cu-Mg based alloys show that [7]:

- during ageing after solution treatment co-clusters are formed

- clusters of sizes that can be reliably detected (typically more than $\sim 10$ atoms) do occur but only a small fraction of the $\mathrm{Cu}$ and $\mathrm{Mg}$ atoms are associated with these larger clusters

- the larger clusters have $\mathrm{Cu}: \mathrm{Mg}$ ratios that vary, with a median value of about 1

Thus atom probe data is fully consistent with the present models on dimer formation, and the experiments show exactly the features that can be expected. Also Nuclear Magnetic Resonance (NMR) [10] and positron annihilation lifetime spectroscopy (PALS) [13] are sensitive to $\mathrm{Cu}-\mathrm{Mg}$ dimer formation. NMR and PALS studies on Al-Cu-Mg alloys have indeed shown that after the rapid hardening reaction the chemical environment of $\mathrm{Cu}$ atoms has changed [10,13], but the published analysis of the experiments fails to identify what this change entails. Microstructural data for two broad groups of experiments (near room temperature and near $150^{\circ} \mathrm{C}$ ) are presented in Table 4. The table includes TEM and selected area diffraction (SAD) on an Al-4wt $\% \mathrm{Cu}-1.5 \mathrm{wt} \% \mathrm{Mg}$ alloy that was solution treated, quenched and aged at room temperature for about a year. This confirmed that no additional diffraction phenomena are observed in SAD and no precipitates can be observed in bright field TEM imaging. 


\begin{tabular}{|c|c|c|c|c|c|}
\hline & Alloy (at\%) & $\mathrm{T}\left({ }^{\circ} \mathrm{C}\right)$ & $\mathrm{t}$ & experiment & observation \\
\hline this work & Al-1.9Cu-1.6Mg & 25 & $10000 \mathrm{~h}$ & TEM & no precipitates resolvable \\
\hline this work & $\begin{array}{l}\text { Al-1.9Cu-1.6Mg } \\
\text { Al-1.9Cu-1.6Mg and }\end{array}$ & 25 & $10000 \mathrm{~h}$ & SAD & no diffraction effects due to precipitates \\
\hline Starink et al [7] & $\begin{array}{l}\text { Al-1.2Cu-1.2Mg } \\
\text { Al-1.9Cu-1.6Mg and }\end{array}$ & 25 & $0-200 h$ & calorimetry & $\mathrm{H}$ decreases strongly*, $\mathrm{H}$ stabilises at about $2 \mathrm{~h}$ \\
\hline Starink et al [7] & Al-1.2Cu-1.2Mg & 50 & $0-200 h$ & calorimetry & $\mathrm{H}$ decreases strongly ${ }^{\star}, \mathrm{H}$ stabilises at about $15 \mathrm{~h}$ \\
\hline Fink et al [67] & Al-1.7Cu-(0.5-1.5)Mg & 30 & $0-10 h$ & dilatometry & expansion \\
\hline Fink et al [67] & Al-1.7Cu-(0.5-1.5)Mg & 31 & $0-10 h$ & dilatometry & $\begin{array}{l}\text { increased resistivity } \\
\text { consistent with } \mathrm{Cu}-\mathrm{Mg} \text { bonds, not with } \mathrm{Cu} \text { in solution, or }\end{array}$ \\
\hline Staab et al [12] & Al-2.0Cu-1.8Mg-0.6Mn & 25 & $120 \mathrm{~h}$ & $\begin{array}{l}\text { XANES } \\
\text { 3DAP - }\end{array}$ & Cu-Cu clustering; \\
\hline Starink et al [7] & Al-1.2Cu-1.2Mg & 25 & $0.5-3.5 h$ & $\begin{array}{l}\text { statistical } \\
\text { 3DAP - }\end{array}$ & $\begin{array}{l}\text { onset of co-clustering happens between } 1 \text { and } 2 \mathrm{~h} \\
\text { clusters with more than } 7 \text { atoms are detectable, but }\end{array}$ \\
\hline Starink et al [7] & Al-1.2Cu-1.2Mg & 25 & 2-30h & imaging & $\begin{array}{l}\text { numbers insignificant } \\
\text { change chemical environment of atoms from } \sim 10 \mathrm{~min} \text { to }\end{array}$ \\
\hline Bastow [10] & Al-1.05Cu-1.7Mg & 21 & $0-645 h$ & NMR & $-30 h$ \\
\hline Ringer et al [21] & $\begin{array}{l}\text { Al-1.1Cu-1.7Mg } \\
\text { Al-1.9Cu-1.6Mg and }\end{array}$ & 20 & $24 \mathrm{~h}$ & hardness & hardening to plateau completed at $24 \mathrm{~h}$ \\
\hline Starink et al [7] & Al-1.2Cu-1.2Mg & 25 & $0-200 h$ & hardness & hardening to plateau occurs between 0.01 and $2 \mathrm{~h}$ \\
\hline Reich et al [68] & Al-1.7Mg-1.1Cu & 150 & $1 \mathrm{~min}$ & TEM & no precipitates resolvable at $1 \mathrm{~min}$ \\
\hline Reich et al [68] & Al-1.7Mg-1.1Cu & 150 & $1 \mathrm{~min}$ & SAD & no precipitates at $1 \mathrm{~min}$ \\
\hline Reich et al [68] & Al-1.7Mg-1.1Cu & 150 & $1 \mathrm{~min}$ & Hardness & hardness reaches plateau within 1 min \\
\hline Reich et al [68] & Al-1.7Mg-1.1Cu & 150 & $1 \mathrm{~min}$ & 3DAP & $\begin{array}{l}\text { Cu:Mg ratio in larger clusters about } 3: 5 \\
\text { Cu-Mg co-clusters detected at } 5 \mathrm{~min} \text {, not detected at }\end{array}$ \\
\hline Reich et al [68] & Al-1.7Mg-1.1Cu & 150 & 1-60min & 3DAP & $1 \mathrm{~min}$ \\
\hline Ringer et al [20] & Al-1.7Mg-1.1Cu & 150 & $5 \min$ & AP & Cu-Mg co-clusters detected at $60 \mathrm{~min}$ \\
\hline Ringer et al [20] & Al-1.7Mg-1.1Cu & 150 & $\begin{array}{l}5 \mathrm{~min} \\
\text { linear heating }\end{array}$ & TEM & no precipitates resolvable at $5 \mathrm{~min}$ \\
\hline Ringer et al [21] & Al-1.1Cu-1.7Mg & 130 & $\begin{array}{l}\sim 10 \min \\
\text { linear heating }\end{array}$ & calorimetry & $\begin{array}{l}\mathrm{H} \text { decreases strongly } \\
\mathrm{H} \text { decreases strongly }\end{array}$ \\
\hline this work & Al-1.2Cu-1.2Mg & 120 & $\sim 10 \mathrm{~min}$ & calorimetry & heating at $10 \mathrm{~K} / \mathrm{min}$ \\
\hline
\end{tabular}

* change in $H$ is about half of that due to formation of the equilibrium phase, the $\mathrm{S}$ phase.

Table 4 Microstructural data on the two broad groups of experiments: ageing experiments performed at room temperature and near $150^{\circ} \mathrm{C}$, for times up to about 10 times the time required to reach the hardness plateau.

The data in Table 4 is fully consistent with the present models for co-clusters, with the exception of one observation by Reich et al [68] who failed to detect $\mathrm{Cu}-\mathrm{Mg}$ co-clusters in a sample aged for 1 min at $150^{\circ} \mathrm{C}$ (by they do detect them after $5 \mathrm{~min}$ ). In the absence of any data supporting this one finding we consider the weight of evidence clearly supports the present models, and we will disregard this one finding. We further investigated literature on TEM, HREM, SAD in TEM, APFIM, 3DAP, calorimetry, NMR and PALS experiments for ageing times within about 10 times the time to reach the plateau hardness (or time to stabilise the enthalpy) in about 50 papers (encompassing [7,12,19,20,23,Error! Bookmark not defined.] and references therein, and references $[10,11,13,15-22,44,51,52,53,65])$, and concluded that the present model is consistent with all the available data. In particular it should be noted that no microstructure investigation ever showed evidence for precipitates (other than co-clusters suggested by APFIM, 3DAP) for ageing times within about 10 times the time to reach the plateau hardness (or time to stabilise the enthalpy). 
This assessment further indicates that the term GPB zones, associated with early decomposition and hardening in $\mathrm{Al}-\mathrm{Cu}-\mathrm{Mg}$ alloys in most of the pre 1995 papers cited in this work, does not reflect accurately the processes involved, and is ultimately obfuscating or, depending on which of the definition of GPB zones is used, even misleading.

Next the first principles model prediction (VSP) was assessed. A first principles total energy calculation (FP-CVM) of 4 atom tetrahedrons provides an enthalpy of mixing of $30 \mathrm{~kJ}$ per mole $\mathrm{Cu}-$ $\mathrm{Mg}$ dimers [25]. This is in good agreement with the present model and analysis, and the small deviation can be due the limitations in accuracy provided by this 4 atom tetrahedrons calculation. We may also compare our results with the enthalpy of mixing for the coherent rod/lath-like structures formed in a later stage of the ageing $\left(24-96 \mathrm{~h}\right.$ at $\left.180^{\circ} \mathrm{C}\right)$ in an $\mathrm{Al}-0.4 \mathrm{at} \% \mathrm{Cu}-3 \mathrm{at} \% \mathrm{Mg}$ alloy [23]. For the coherent rod/lath-like structures identified by Kovarik et al. [23], $5 \times 5 \times 1$ and $6 \times 6 \times 1$ supercell calculations determine an enthalpy of formation of $48 \mathrm{~kJ}$ per mol solute atoms in the GPB structure [23]. Thus these coherent rod/lath-like structures are more stable then the $\mathrm{Cu}-\mathrm{Mg}$ dimers and should be considered a stage of the ageing of the alloys that is subsequent to the co-cluster formation.

An alternative treatment for thermodynamics of clusters suggested in the literature [24] involves a quasi-chemical model which takes nearest neighbour interactions into account. Analysis of this model showed that it can not explain all the experimental observations. Particularly, this model can not reconcile the observations that immediately after water quenching no $\mathrm{Cu}-\mathrm{Mg}$ co-clustering is detected, with the enthalpy of formation of $\mathrm{Cu}-\mathrm{Mg}$ co-clustering being of the order determined here.

\section{Strength models for co-clusters: comparison with previous models}

The present model for co-cluster strengthening indicates that the yield strength of alloys which contain only co-clusters as strengthening precipitates is in good approximation proportional to the amount of the co-clusters. This is different in previous models for co-cluster strengthening (and the vast majority of other precipitation strengthening mechanisms) which predict a square root of the amount (or square root of volume fraction) dependency. This allows us to test the model in the following fashion. We have performed hardness tests on an $\mathrm{Al}-1.2 \mathrm{at} \% \mathrm{Cu}-1.2 \mathrm{at} \% \mathrm{Mg}$ alloy during room temperature ageing for time $t_{\mathrm{NA}}$, and also performed DSC experiments on samples of the same alloy subjected to the same natural ageing treatments. The DSC thermograms are presented in Fig. 8. The total change in heat released during the DSC experiment for each naturally aged sample, $\Delta Q\left(t_{\mathrm{NA}}\right)$, was measured and the change during ageing, $\Delta Q\left(t_{\mathrm{NA}}\right)-\Delta Q\left(t_{\mathrm{NA}}=0\right)$, was determined. The latter difference, $\Delta Q\left(t_{\mathrm{NA}}\right)-\Delta Q\left(t_{\mathrm{NA}}=0\right)$, should be proportional to the amount of co-clusters formed during ageing, and the amount of co-clusters thus obtained is plotted as a function of the hardness in Fig. 9. (One further data point for $\mathrm{Al}-1.9 \mathrm{at} \% \mathrm{Cu}-1.6 \mathrm{at} \% \mathrm{Mg}$ aged for $100 \mathrm{~h}$ is added.) The graph of $f$ vs HV shows a linear correlation, which further supports the present strengthening model, whilst clearly showing strength increments are not proportional to $f^{1 / 2}$.

In several works (e.g. [38]), including some from the present group (e.g. [7,57]), strengthening by co-clusters has been modelled by considering only modulus hardening is effective. Eq. 14 (the simplified form for modulus hardening) was applied in these works, and through fitting of $\mu_{\mathrm{cl}}$ 
generally good results were obtained. Whilst the present work indicates that this approach is mistaken in terms of the identification of the fundamental processes at work, it can be seen that fitting a value for $\mu_{\mathrm{cl}}$ higher than the actual value of $\mu_{\mathrm{cl}}$ can provide an effective fit for a limited range of data.

We further note that the present co-cluster hardening model provides an explanation for a range of observations in ternary and higher order alloys. For example, through combining Eqs. 6, 9, 13 and 19, and assuming solution strengthening is substantially less than co-cluster strengthening, the increase in strength of an alloy on formation of co-clusters is proportional to the change in enthalpy during co-cluster formation. Such a proportionality is found for $\mathrm{Al}-1.7 \% \mathrm{Li}-\mathrm{Cu}-\mathrm{Mg}$ alloys that were exposed for $1000 \mathrm{~h}$ at $70^{\circ} \mathrm{C}$ following an solution treating and an ageing treatment at $150^{\circ} \mathrm{C}$ [69] and the proportionality constant is consistent with the present model. This secondary ageing treatment does not cause any changes in microstructure that can be detected by TEM. This shows that the magnitude of secondary age hardening in this alloy can be quantitatively explained by the formation of co-clusters.

It is also noted that the present models show that co-clusters impart both a significant strength and, as a result of the strong decrease resistance to dislocation movement on passage of a one dislocation, they also cause an unusually high propensity for shear localisation. In fatigue loading conditions the shear localisation would cause a propensity for roughness induced crack closure (RICC) [8], provided grains are reasonably large. Thus an alloy with high amounts of co-clusters would be ideal for applications requiring fatigue resistance and strength, and optimisation of these mechanical properties would be achieved through maximising the co-cluster content. Published calorimetry and APFIM work on a range of alloys have indicated that of the light f.c.c. metallic alloys $\mathrm{Al}-\mathrm{Cu}-\mathrm{Mg}$ have the highest co-cluster content. From this information we can now determine the composition of the optimum alloy for specific strength and fatigue resistance in the following way:

- Our model shows that underaged Al-Cu-Mg alloys with $\mathrm{Cu}: \mathrm{Mg}$ content close to 1 and $\mathrm{Cu}$ and $\mathrm{Mg}$ solute levels close to the maximum solubility should provide maximum co-cluster content. Using phase diagrams of ternary alloys this indicates an $\mathrm{Al}-1.6 \mathrm{Cu}-1.6 \mathrm{Mg}$ alloy.

- We also consider that $\mathrm{Mn}$ additions at levels of about 0.2 at $\%$ are effective in promoting recrystallisation through formation of $\mathrm{T}-\mathrm{Al}_{20} \mathrm{Cu}_{2} \mathrm{Mn}_{3}$ dispersoids [26], which are to a large extend not dissolvable in the Al-rich phase. Thus Mn

additions will remove some $\mathrm{Cu}$ from solid solution and also $\mathrm{Fe}$ impurities will remove some $\mathrm{Cu}$ from solid solution (through formation of $\omega-\mathrm{Al}_{7} \mathrm{Cu}_{2} \mathrm{Fe}$ ); and it is clear that the best alloys for specific strength and fatigue resistance (and commercially viable impurity levels) should be $\mathrm{Al}-1.8 \mathrm{Cu}-1.6 \mathrm{Mg}-0.2 \mathrm{Mn}-0.05 \mathrm{Fe}$ alloys in underaged conditions.

The latter compositions and heat treatment are essentially identical to $2 \times 24-\mathrm{T} 3$ alloys, which are dominant in applications requiring a high specific strength and fatigue resistance, such as airplane fuselage and lower wing. Thus this analysis provides a rationale for alloy optimisation, linking atomic scale processes to properties at the component scale (wings and fuselage). 


\section{Conclusions}

A thermodynamic model for co-clusters based on a single interaction energy of dissimilar nearest neighbour interaction energy is presented. Also a model for the strengthening due to these cocluster dimers is derived. The model includes a new treatment of (short-) order strengthening relevant to these co-clusters and further encompasses modulus hardening and chemical hardening. Evaluation shows that in general (short-) order strengthening will be the main strengthening mechanism. The model is tested against data on $\mathrm{Al}-\mathrm{Cu}-\mathrm{Mg}$ alloys. It is shown that:

- The thermodynamic model can fully explain published and new data on the heat evolution due to co-cluster formation. The $\mathrm{Cu}-\mathrm{Mg}$ interaction enthalpy $\Delta H_{\mathrm{A}-\mathrm{B}}$ is determined as $34.5 \pm 0.5 \mathrm{~kJ} / \mathrm{mol}$.

- The models can quantitatively predict the very first stage of hardening and associated heat evolution in $\mathrm{Al}-\mathrm{Cu}-\mathrm{Mg}$ alloys with $\mathrm{Mg}: \mathrm{Cu}$ ratio between 20 and 0.5 , and $\mathrm{Cu}$ contents between about 0.1 and 2 at\%. The process of co-cluster formation is consistent with published data on microstructural evolution for relevant $\mathrm{Al}-\mathrm{Cu}-\mathrm{Mg}$ alloys.

- The model is successfully tested against data on strength and hardness of a wide range of Al-Cu$\mathrm{Mg}$ alloys treated at temperatures between 20 and $220^{\circ} \mathrm{C}$.

- The term GPB zones, often associated with early decomposition and hardening in $\mathrm{Al}-\mathrm{Cu}-\mathrm{Mg}$ alloys, does not reflect accurately the processes involved, and is ultimately obfuscating or, depending on which of the definition of GPB zones is used, even misleading.

- Co-cluster formation involving dimers causes strength increments that are in good approximation proportional to the change in enthalpy of the alloy, and the proportionality constant is derived. This proportionally is seen in $\mathrm{Al}-\mathrm{Li}-\mathrm{Mg}-\mathrm{Cu}$ alloys exposed at $70^{\circ} \mathrm{C}$, which strongly indicates that strengthening during low temperature exposure is due to formation of 2 atom co-clusters.

\section{Acknowledgements}

The following people are gratefully acknowledged: Ms. A. Dion, and Drs J.L. Yan, Z. Zhu and N. Gao for performing selected DSC experiments, Dr N. Gao for performing tensile tests on a 2024 alloy, Dr G. Mahon for thermomechanical processing of Alloy 2b, Drs G. Mahon, S. Court and L. Kovarik for discussions on low $\mathrm{Cu}$ Al-Mg-Cu-Mn alloys. QinetiQ (Farnborough, UK), Alcan (former Banbury Labs), Airbus UK and Prof M.J. Mills and Dr L. Kovarik are gratefully acknowledged for providing alloys.

\section{Appendix: Undissolved intermetallics}

Insoluble or undissolved particles and dispersoids, such as $\omega-\mathrm{Al}_{7} \mathrm{Cu}_{2} \mathrm{Fe}, \mathrm{S}-\mathrm{Al}_{2} \mathrm{CuMg}, \mathrm{T}-$ $\mathrm{Al}_{20} \mathrm{Cu}_{2} \mathrm{Mn}_{3}, \mathrm{Al}_{12}(\mathrm{Fe}, \mathrm{Mn})_{3} \mathrm{Si}$ and $\mathrm{Al}_{6}(\mathrm{Fe}, \mathrm{Mn})$, which form during solidification or homogenisation, can be present in Al-Cu-Mg type alloys with $\mathrm{Mn}, \mathrm{Fe}$ and $\mathrm{Si}$ additions and impurities [26,27]. Since the presence of $\omega, \mathrm{S}$ and $\mathrm{T}$ phases will remove some $\mathrm{Cu}$ and $\mathrm{Mg}$ from the solid solution, it is necessary to calculate the effective solute concentration in the matrix after solution heat treatment. 
The atomic fraction of undissolved $\omega-\mathrm{Al}_{7} \mathrm{Cu}_{2} \mathrm{Fe}$ can be calculated based on the solubility of $\mathrm{Fe}$ in $\mathrm{Al}$ matrix, since the solubility of $\mathrm{Fe}$ is not significantly influenced by the additions of $\mathrm{Cu}$ or $\mathrm{Mg}$ [70]. At typical $T_{S H T}$ for 2024 alloys, which is about $500^{\circ} \mathrm{C}$, the maximum solubility of Fe in $\mathrm{Al}, x_{F e}^{e}$, is 0.0055 wt.\% [71]. The amount of $\omega-\mathrm{Al}_{7} \mathrm{Cu}_{2} \mathrm{Fe}$ in the alloy is then given by:

$$
x_{\omega}=10\left(x_{F e}^{g}-x_{F e}^{e}\right)
$$

where $x_{F e}^{g}$ is the gross Fe content of the alloy. A similar treatment is applied to obtain the amount of $\mathrm{Al}_{20} \mathrm{Cu}_{2} \mathrm{Mn}_{3}$. Based on the solvus of $\mathrm{Al}_{20} \mathrm{Cu}_{2} \mathrm{Mn}_{3}$ in the $\mathrm{Al}-\mathrm{Cu}-\mathrm{Mn}$ system, at $500^{\circ} \mathrm{C}$ the solubility of $\mathrm{Mn}$ in $\mathrm{Al}$ with a $\mathrm{Cu}$ content of $4 \mathrm{wt} \%$, is about $0.2 \mathrm{wt} \%$ [70]. Thus the amount of $\mathrm{T}-\mathrm{Al}_{20} \mathrm{Cu}_{2} \mathrm{Mn}_{3}$ in the alloy is given by:

$$
x_{T}=25 / 3\left(x_{M n}^{g}-x_{M n}^{e}\right)
$$

where $x_{M n}^{g}$ is the gross Mn content of the alloy.

In alloys for which the $\mathrm{Cu}$ and $\mathrm{Mg}$ contents are close to the solvus of $\mathrm{S}$ phase at the homogenising treatment, some undissolved $\mathrm{S}$ phase can be present. FEG-SEM investigation of alloys $2 \mathrm{~b}, 3$ and 4 showed that only alloy 4 contained undissolved S phase. DSC experiments showed that this alloy has an $\mathrm{S}$ phase solvus temperature within about $10^{\circ} \mathrm{C}$ of the solution heat treatment temperature, $T_{\mathrm{SHT}}$, whilst for the other two the difference is at least $30^{\circ} \mathrm{C}$. Thus we will consider that for all alloys with an $\mathrm{S}$ phase solvus temperature more than $30^{\circ} \mathrm{C}$ below $T_{\mathrm{SHT}}$ all $\mathrm{S}$ phase is dissolved. For all other alloys we will estimate $\mathrm{S}$ phase content from available experimental data. An accurate calculation of the amount of S phase in alloy 4 is provided by the difference between the amounts of intermetallic phases detected in alloys 3 and 4 . This provides $V_{S}=0.009$ for alloy 4 . For the 2524 alloy in [60] we can estimate the amount of S phase from optical micrographs in [60] as about half that of our alloy 4.

The effective solute concentration in the matrix after solution treatment is obtained by from the difference of the gross content and the amounts in the undissolved phases.

\section{References}

1 E.V. Pereloma, A. Shekhter, M.K. Miller and S.P. Ringer. Acta Mater. 2004,52:5589.

2 E.V. Pereloma, I.B. Timokhina, K.F. Russell, M.K. Miller. Scripta Mater. 2006, 54:471.

3 Moody, MP; Stephenson, LT; Liddicoat, PV, Ringer SP. Microsc. Res. Techn. 2007, 70:258

4 Stephenson LT, Moody MP, Liddicoat PV, Ringer SP. Microsc. \& Microanal. 2007,13:448

5 T. Honma, S. Yanagita, K. Hono, Y. Nagai, M. Hasegawa. Acta Mater. 2004, 52, 1997

6 Serizawa A, Hirosawa S, Sato T, Metall Mater Trans A 2008, 3: 243-251

7 M.J. Starink, N. Gao, L. Davin, J. Yan, A. Cerezo. Phil. Mag. 2005, 85: 1395

8 N. Kamp, N. Gao, M.J. Starink, I. Sinclair. Int. J. Fatigue 2007, 29: 869-878

9 J.C. Williams, E.A. Starke, Acta Mater 2003, 51: 5775-5799

10 Bastow TJ, Phil.Mag. 2005, 85: 1053

11 Bastow TJ, Hill AJ. Mater. Sci. For. 519-521: 1355-1360, 2006.

12 T.E.M. Staab, M. Haaks, H. Modrow. Appl Surf Sci 2008, 255, 132-135.

13 B. Klobes, T.E.M. Staab, M. Haaks, K. Maier and I Wieler. Phys Stat Sol 2008, 2, A61 - A66.

14 H.K. Hardy, J. Inst. Metals 1954-55, 83: 17.

15 J.T. Vietz, I.J. Polmear. J. Inst. Metals 1966, 94: 410.

16 T. Takahashi, T. Sato. J. Jpn. Inst. Light Metals 1985, 35, 41.

17 Y. Nagai, M. Murayama, Z. Tang, T. Nonaka, K. Hono and M. Hasegawa, Acta Mater. 49 (2001) 913. 
18 S. Abis, M. Massazza, P. Mengucci, G. Riontino. Scr. Mater. 2001,45: 685.

19 M.J. Starink, A. Cerezo, J. Yan, N. Gao. Philosoph. Mag Lett 2006, 86:243

20 S.P. Ringer, T. Sakurai, I.J. Polmear. Acta Mater. 1997, 45: 3731.

21 S.P. Ringer, S.K. Caraher, I.J. Polmear. Scr. Mater. 1998, 39: 1559.

22 A.-M. Zahra, C.Y. Zahra. Phil. Mag. Lett. 2002, 82: 9

23 L. Kovarik, S.A. Court, H.L. Fraser, M.J. Mills. Acta Mater 2008, 56: 4804-4815

24 Aiwu Zhu, B.M. Gable, G.J. Shiflet, E.A. Starke. Acta Mater. 2004, 52: 3671

25 Aiwu Zhu, Jr., E.A. Starke and G.J. Shiflet. Scripta Mater. 2005, 53: 35

26 S.C. Wang, M.J. Starink. Int Mater Rev., 2005, 50:193

27 F. Bron, J. Besson, A. Pineau. Mater. Sci. Eng. A 2004, 380;356.

28 A.J. Ardell. Metall. Trans. A. 1985, 16: 2131.

29 C. Schlieser and E. Nembach. Acta Metall. Mater. 1995, 43:3983.

30 V. Gerold, H.J. Gudladt and J. Lendvai. Phys Stat Sol A 1992, 131:509

31 E. Nembach. Scr. Mater 1997, 36:1409.

32 S.M. Jeon, J.K. Park, Acta Mater. 1996, 4: 1449

33 A.R. Büchner. W. Pitsch. Z. Metallkde 1985, 76: 651.

34 P.A. Flinn. Acta Metall 1958, 6: 631

35 G. Kostorz. B. Schonfeld. Chimia 2001,55:517

36 T. Mohri, H. Miyamoto, Y. Terada,d T. Suzuki. Mater Sci Eng A 1999, 267:151

37 L. Cartaud, J. Guillot and J. Grilhe. Proc of ICSMA IV, Nancy, 30 August-3 September 1976, vol. 1, (Ed. Laboratoire de Physique du Solide ENSMIN-INPL, Nancy) p. 214 (1976).

38 P. Gomiero, Y. Brechet, F. Louchet, A. Tourabi, B. Wack. Acta Metall. Mater. 1992, 40:857.

39 C.J. Smithells, Metals Reference Book, $7^{\text {th }}$ Ed., Butterworths-Heinemann, London, 1992.

40 E. Nembach. Phys. Stat. Sol. A, 1983, 78, 571

41 S.C. Wang, Z. Zhu. M.J. Starink, J. Microscopy, 2005, 217: 174.

42 Z. Zhu, M.J. Starink. Mater Sci Eng A, 2008, 488: 125

43 M.J. Starink, Int. Mater. Rev. 2004, 49: 191

44 M.J. Starink and A. Dion, Thermochim Acta 2004, 417:5

45 J. Yan, PhD thesis, University of Southampton, 2006

46 L. Kovarik, P.I. Gouma, C. Kisielowski, S.A. Court, M.J. Mills. Mater. Sci. Eng. 2004 A387-389: 326

47 L. Kovarik, P.I. Gouma, C. Kisielowski, S.A. Court and M.J. Mills, Acta Mater. 2004, 52:2509

48 M.J. Starink. Thermochim. Acta, 2003, 404:163

49 I.N. Khan and M.J. Starink. Mater. Sci. Techn., 2008, 24: 1403-1410

50 M.J. Starink and P.J. Gregson. Scr. Metall. Mater. 1995, 33: 893

51 L. Davin. PhD thesis, Oxford University, 2004

52 A.-M. Zahra, C. Zahra and B. Verlinden. Phil Mag Lett. 2006, 86:235

53 B. Verlinden, A.-M. Zahra. Mater. Sci. Forum 2003, 426-432: 423

54 Charai, A., Walther, T., Alfonso, C., Zahra, A. M., Zahra, C. Y.: Acta Mater. 2000, 48:2751

55 M.J. Starink, A. Deschamps, S.C. Wang. Scr Mater, 2008, 58: 377

56 I.N. Khan, M.J. Starink, J.L. Yan. Mater. Sci. Eng. A, 2008,472:66

57 Z. Zhu, M.J. Starink. Mater. Sci. Eng. A 2008, 489:138

58 Weilong Hu. Int. J. Plast. 2007, 23:620

59 R.N. Wilson, D.M. Moore, P.J.E. Forsyth. J Inst Met 1967, 95: 177

60 I.J. Polmear, Trans Met Soc AIME 1964, 230: 1331

61 K. Raviprasad, ICAA9, 2-5 August 2004, Brisbane, Australia (poster)

62 G.B. Winkelman, K. Raviprasad, B.C. Muddle. Mater Sci Forum 2002, 396:1037

63 J.R. Davis (ed.), ASM Specialty Handbook Aluminum and Aluminum Alloys (ASM International) 1993

64 T.S. Srivatsan, D. Kolar and P. Magnusen. Materials \& Design 2002, 23:129.

65 P. Ratchev, B. Verlinden, P. De Smet and P. Van Houtte, Acta Mater. 1998, 46:3523.

66 S.A. Court, L. Kovarik and M.J. Mills. unpublished research, 2006

67 W.L. Fink, D.W. Smith, L.A. Willey. in 'Age Hardening of Metals', Symposium on Precipitation Hardening, Chicago, Oct 23-27, 1939, American Society for Metals (1940).

68 L. Reich, S.P. Ringer and K. Hono. Phil. Mag. Lett. 1999, 79:639.

69 S. Katsikis, B. Noble, S.J. Harris. Mater Sci Eng 2008, A485; 613.

70 P. Villars, A. Prince, H. Okamoto (Eds.). Handbook of ternary alloy phase diagrams, ASM International, Materials Park, OH, 1994.

71 H.W.L. Phillips. 'The constitution of alloys of aluminium, copper and iron', J. Inst. Met., 1953-54, 82: 197. 